\title{
Influence of fatigue and aggressive exposure on GFRP girder to SFRSCC deck all-adhesive connection
}

\author{
P.J.D. Mendes ${ }^{1}$, J.A.O. Barros ${ }^{2}$, J.M. Sena-Cruz ${ }^{3}$, M. Taheri ${ }^{4}$
}

\begin{abstract}
To assess the influence of fatigue loading and environmental conditions on the bond behavior between glass fiber reinforced polymer (GFRP) systems and steel fiber reinforced self-compacting concrete (SFRSCC) that are adhesively bonded, an experimental program composed of push-out tests was carried out. The following three scenarios were selected for the environmental conditions: natural conditions; wet-dry cycles; and temperature cycles. Half of the specimens were submitted to monotonic loading up to failure, and the other half were submitted to a fatigue load configuration of 1-million cycles and then subjected to a monotonic loading up to failure. The results have shown that for the investigated environmental conditions the GFRP-SFRSCC push-out specimens never failed up to 1 million cycles. However, temperature cycles caused a considerable reduction on the stiffness and load carrying capacity in the specimens submitted to fatigue loading, while wet-dry cycles did not modify significantly the maximum shear stress transfer in the investigated connection. This paper describes in detail the experimental program, presenting and discussing the relevant results.
\end{abstract}

\section{Keywords}

Pedestrian bridge; Composites; GFRP pultruded profiles; Fiber reinforced self-compacting Concrete; Composite action; Aggressive exposure

\section{Introduction}

There is always a need for innovative and durable structural load-bearing systems to accelerate construction, especially in bridges. The application of Fiber Reinforced Polymer (FRP) materials is gaining a strong momentum in structural engineering applications [1], particularly in bridges, which are typically exposed to harsh environments. Pultruded FRP shapes have the potential to replace steel sections for bridges and buildings [2]. For this purpose, Glass Fiber Reinforced Polymer (GFRP) is being dominantly used rather than other types of FRP materials, such as carbon or aramid FRPs, because of its reasonable cost. However the uses of composites in bridge construction are still not that common, and a majority of built bridges must consider to be prototypes, such as Hayes et al. [3], Keller [4] and Mendes et al. [5].

\footnotetext{
${ }^{1}$ Researcher, ISISE, University of Minho, Dep. of Civil Engineering, 4800-058 Guimarães, Portugal,

${ }^{2}$ Full Professor, ISISE, University of Minho, Dep. of Civil Engineering, 4800-058 Guimarães, Portugal. Tel: +351 253510 210, Fax: +351 253520 217, barros@ civil.uminho.pt (Corresponding author).

${ }^{3}$ Associate Professor, ISISE, University of Minho, Dep. of Civil Engineering, 4800-058 Guimarães, Portugal

${ }^{4} \mathrm{PhD}$ student, ISISE, University of Minho, Dep. of Civil Engineering, 4800-058 Guimarães, Portugal
} 
When compared to traditional materials such as steel, concrete or timber, FRP materials present several benefits [6]: mainly superior corrosion resistance, stiffness-to-weight and strength-to-weight ratios, low thermal expansion, non-magnetic properties, damage tolerance and ease of transportation and handling.

FRP materials present higher unit price when compared with conventional materials. However, due to the lower costs of transportation, installation, maintenance, and life cycle, constructive systems based on FRP materials become very competitive [7]. Due to superior durability of FRP materials, in many cases composite structures can last much longer than the ones made of conventional materials, yielding lower life-cycle cost [8].

The research carried out in this paper is part of a three-year research project funded by ADI (Portuguese Innovation Agency) to develop permanent pedestrian bridge systems using Steel Fiber Reinforced Self-Compacting Concrete (SFRSCC) decks and Glass Fiber Reinforced Polymer (GFRP) girders (see Fig. 1). During the first phase of the project, the creep, as well as the structural behavior of the pedestrian bridge was investigated [5]. Two different connections configurations between the deck and the girder were evaluated. The former using steel anchors, glued to the concrete deck by an epoxy adhesive, then bolted to the GFRP profiles, with the deck surfaces also glued to the GFRP girders by an epoxy adhesive (see Fig. 2). The latter using adhesive alone to glue the deck and the girder. Numerical simulations were carried out to appraise the possibility of using an all-adhesive connection. The results showed that for the serviceability limit states and for the ultimate limit states, the load carrying capacity of the bridge structure is not affected by using an alladhesive connection between the deck and the girders. However, it was mentioned that further investigation should be carried out to appraise the response of the connection under extreme conditions.

Therefore, the present research focuses on the adhesively bonded deck-to-girder connection behavior, under static and fatigue loading, when exposed to temperature and wetdry cycles.

\section{Experimental program}

\subsection{Material properties}

Table 1 shows the mixture composition of the developed SFRSCC, and Table 2 presents the relevant rheological and mechanical properties of this material [9, 10], respectively. $60 \mathrm{~kg} / \mathrm{m}^{3}$ of hooked ends steel fibers of $35 \mathrm{~mm}$ length, $0.55 \mathrm{~mm}$ diameter and $1100 \mathrm{MPa}$ tensile strength were used. The methodology followed to formulate the SFRSCC composition is mainly based on the following three steps [9]: (i) the proportions of the constituent materials of the binder paste are defined; (ii) the proportions of each aggregate on the final granular skeleton are determined; (iii) binder paste and granular skeleton are mixed in distinct proportions until self-compacting requirements in terms of spread ability, correct flow velocity, filling ability, blockage and segregation resistance are assured, allowing the determination of the optimum paste content in concrete.

The GFRP profiles were produced by the pultrusion process and are composed by $65 \%$ in volume of E-glass fibers embedded in a polyester matrix. The fiber systems is composed of $97 \%$ of E-glass roving type and 3\% of E-glass continuous filament mat (CFM). The production speed of these GFRP profiles is $0.3 \mathrm{~m} /$ minute at a temperature and humidity of $180{ }^{\circ} \mathrm{C}$ and $55 \%$ in the die, respectively. The transition temperature of the polyester matrix is $87^{\circ} \mathrm{C}$. From an extensive experimental program for the characterization of the relevant 
properties of the type of GFRP profile used in the present research, the values indicated in Table 3 were determined [12]. The "S\&P Resin 220" epoxy adhesive used to glue the GFRP profiles to the SFRSCC panels was applied cured at room temperature. According to the supplier this epoxy adhesive presents a bending tensile strength of $30 \mathrm{MPa}$, a compressive strength of $90 \mathrm{MPa}$ and bulk shear strength of $3 \mathrm{MPa}$. By executing tensile tests according to the ISO 527-2:1993 standard [13] Sena et al. [14] obtained for the average tensile strength and the average Young's modulus the value of $21 \mathrm{MPa}$ and $7.7 \mathrm{GPa}$, respectively. The glass transition temperature $(\mathrm{Tg})$ of this adhesive is $55^{\circ} \mathrm{C}$ [11]. The long-term properties of this epoxy adhesive were assessed experimentally by Costa and Barros [15].

\subsection{Test specimens, setup and instrumentation}

Fig. 3 shows the push-out test specimens used in the present research. The specimens consist of two concrete panels $\left(400 \times 250 \times 40 \mathrm{~mm}^{3}\right)$ adhesively bonded to each flange of the GFRP profile. The GFRP profiles were bonded to the SFRSCC panels when the SFRSCC age was 21 days. The cross-section of the GFRP profile is a I-shape with $200 \mathrm{~mm}$ height, $100 \mathrm{~mm}$ wide and a constant thickness of $10 \mathrm{~mm}$. The adhesive volume in the bond between the flange of the GFRP and the SFRSCC panel is $350 \times 100 \times 2.0 \mathrm{~mm}^{3}$. A needle scaler was used to ensure that the concrete laitance was removed before bonding the GFRP profiles to concrete. Then, a spatula trowel was used to apply the adhesive on the concrete surface. The surfaces of the GFRP profiles were treated by using sandpaper to improve the adherence between epoxy adhesive and GFRP profile. After the fabrication process, the specimens were left in a room at an ambient temperature of $22{ }^{\circ} \mathrm{C}$ for 7 days, allowing a complete cure of the adhesive.

To ensure minimum friction between the concrete panels and the supporting steel frame (see Fig. 4), rectangular plates of neoprene were used. Additionally, to prevent any suddenly failure of the specimen, a passive confinement system was used, as shown in Fig. 4.

A total of 18 specimens were tested. The specimens were divided into three series according to the type of exposure used: reference exposure, temperature cycles, and wet-dry cycles. The first character in the specimen ID indicates the series number ( $R$ for reference, $T$ for temperature cycles and WD for wet-dry cycles), the middle character specifies the loading type, such as S for static, F for fatigue and PF for post-fatigue, and the last character gives the specimen number. As an example, R_S1 stands for the reference specimen number one submitted to static loading.

The push-out specimens were tested with a vertical pushing load, as shown in Fig. 4. The monotonic load and the fatigue load were applied using a $500 \mathrm{kN}$ servo-hydraulic actuator incorporating a load cell of $500 \mathrm{kN}$.

To measure the slip between the flanges of the GFRP profile and SFRSCC, five LVDTs (LVDT 1 to 5) with a stroke of $5 \mathrm{~mm}$ were placed with a regular pattern in four different locations along the bond length (see Fig. 3). The supports used to hold these LVDTs are perfectly aligned in the horizontal plan. Two LVDTs of $10 \mathrm{~mm}$ stroke were used (LVDT 6 and 7) to measure the relative horizontal movement of the concrete panels (see Fig. 3).

\subsection{Exposure environments}

The connection system proposed in the present paper is intended to be used in a fullscale composite pedestrian bridge to be installed in the north of the Portuguese territory. Thus, to ensure a long service live and guarantee its proper functioning, with minimal maintenance, 
is essential to estimate the long-term behavior of such connection under different environmental conditions. Therefore, the exposure conditions chosen for this research were based on the characteristics of the actual environment to which the bridge structure will be exposed.

The north of the Portuguese territory features the Mediterranean climate, with warm, dry summers and mild rainy winters. Summers are typically sunny with average temperatures between $14{ }^{\circ} \mathrm{C}$ and $28{ }^{\circ} \mathrm{C}$, but can rise to as high as $40{ }^{\circ} \mathrm{C}$ during occasional heat waves. During such heat waves the humidity can reach $95 \%$; however, during summer, the average relative humidity is $80 \%$. Winter temperatures typically range between $4{ }^{\circ} \mathrm{C}$ during morning and $14{ }^{\circ} \mathrm{C}$ in the afternoon but rarely drop below $0{ }^{\circ} \mathrm{C}$ at night [16].

Based on such conditions, two different types of exposure were considered for the present research: alternate wet-dry cycles and temperature variation cycles. In addition, one group of specimens was kept in the laboratory as control specimens. Details of specimens tested under various exposure regimes are shown in Table 4. Both exposure conditions were applied after the epoxy adhesive has been cured during at least 7 days.

In the alternate wet-dry exposure, each cycle consisted of complete immersion of the specimens in $3 \% \mathrm{NaCl}$ solution for 12 hours followed by drying in air another 12 hours. The $\mathrm{NaCl}$ solution was used to simulate the worst-case scenario, where the structure is located near the shore. For such cycles two separate containers were used, each one equipped with a water pump programed to pump the water for one container to another in each 12 hours. The water was kept at $20{ }^{\circ} \mathrm{C}$ using a thermostat during immersion, and the air was kept approximately at $25{ }^{\circ} \mathrm{C}$ during the drying period using a thermo ventilator. Two small pumps were installed in each container to circle the water, avoiding the sedimentation of the salt as well as the water impurities.

A total of 100 cycles were repeated with the described conditions. The amount of salt in the water was decided from the stipulated guidelines provided by ASTM B 117-85 for salt spray (fog) testing. The $\mathrm{pH}$ of the solution was found between 7.5 and 8.0.

In the temperature cycle exposure, a climatic chamber was used with temperature and humidity regulation capability. A typical cycle of temperature variation with time used in the tests is shown in Fig. 5, i.e. six cycles a day with maximum and minimum temperatures of $60{ }^{\circ} \mathrm{C}$ and $-10{ }^{\circ} \mathrm{C}$, respectively. The specimens were exposed to a total of 100 cycles, with a $\mathrm{RH}$ of $80 \%$ during positive temperatures, and approximately $10 \%$ during negative temperatures.

\subsection{Test procedures}

To develop an all-adhesive connection for use in pedestrian bridge systems, it is essential to analyze the bond behavior under different exposure and loading conditions. Thus, three different load scenarios were used: static load, fatigue load and post-fatigue static load.

The static load allows the determination of the bond-slip relationship, as well as the ultimate bond strength. The fatigue loading allows the assessment of the connection behavior at long-term. And lastly, the post-fatigue static load allowed the evaluation of the changes in the stiffness and bonding capabilities after fatigue loading.

The static load and the post-fatigue static load tests were carried under displacement control mode. The static load was applied monotonically until failure. The displacement rate $0.2 \mathrm{~mm} / \mathrm{min}$ was adopted to control the test with the internal LVDT of the actuator. The 
fatigue load was determined based on previous tests and numerical simulations of the bridge structure [5], which allowed the determination of the maximum shear stress in the GFRPconcrete connection for the serviceability limit states. Therefore, to determine the load to obtain the equivalent shear stress, one reference specimen was monitored with strain gauges under static load. The strain gauges were positioned at the level of a horizontal plane, one crossing LVDT 1, and the other passing LVDT 5, and were bonded to the concrete and to the flange's GFRP profile. The obtained results allowed the determination of the fatigue load range. Hence, the fatigue tests were carried out at maximum and minimum stress ratios of $\mathrm{S}_{\max }\left(\mathrm{F}_{\max } / \mathrm{F}_{\text {ult }}\right)=0.48$ and $\mathrm{S}_{\min }\left(\mathrm{F}_{\min } / \mathrm{F}_{\text {ult }}\right)=0.14$. All tests ran at a load ratio $\mathrm{R}\left(\mathrm{F}_{\min } / \mathrm{F}_{\max }\right)=$ 0.28 . Therefore, the specimens were firstly loaded statically up to $90 \mathrm{kN}$, and then the fatigue load was applied between $40 \mathrm{kN}$ and $140 \mathrm{kN}$, corresponding to a variation of $\pm 50 \mathrm{kN}$. All specimens were subjected to 1 million sinusoidal load cycles at a frequency of $2 \mathrm{~Hz}$, and the sinusoidal loading was force controlled. The cycle readings were taken at the following rate: every 1000 cycles 10 cycles were recorded. Note that in the subsequent sections the results showed are for the representative push-out specimen from the three specimens tested.

\section{Test results and discussion}

\subsection{Monotonic tests}

Table 5 shows the results and statistical data for the monotonic and post-fatigue monotonic behavior series. Note that in the subsequent sections the analysis of the results is carried out in specimens assumed to be representative of the push-out tests of the three environmental conditions. Thus, for the monotonic series the R_S2, T_S3 and WD_S1 were adopted, while for the post fatigue series the R_PF3, T_PF1 and WD_PF3 were selected for this purpose.

Fig. 6 shows the typical load versus loaded end slip (LVDT1, Fig. 3) curves for the three different environmental exposures (see also Table 5). The control exposure (R series) exhibited the highest peak load (at the failure of the specimen), reaching approximately $315 \mathrm{kN}$, with a loaded end slip of $69 \mu \mathrm{m}$. The results from temperature cycles exposure (T series) reveal that, when compared to the ones of the control exposure, the peak load and the loaded end slip decreased significantly, reaching $183 \mathrm{kN}$ and $42 \mu \mathrm{m}$, respectively, representing a reduction of $41 \%$ in terms of load carrying capacity. This behavior was a consequence of the stress cycles imposed by the temperature cycles. Also, the temperature cycles exceeded the $\mathrm{T}_{\mathrm{g}}\left(55^{\circ} \mathrm{C}\right)$, which, according to Moussa et al. [17], has a negative impact on the bond strength and stiffness.

Considering the wet-dry cycles (WD series), the results show an increase of the specimen stiffness up to a load of about $150 \mathrm{kN}$, then the stiffness remained identical to the control exposure up to a load of about $250 \mathrm{kN}$, followed by a decrease in the bond stiffness. The peak load also decreased slightly, reaching $296 \mathrm{kN}$ with a loaded end slip of $48 \mu \mathrm{m}$, corresponding to a reduction of approximately $6 \%$ and $30 \%$, respectively, when compared to the control exposure. The increase of the initial stiffness for the WD series could be explained by the less aggressive and best curing conditions provided by the WD exposure, i.e., the temperature ranged between $20^{\circ} \mathrm{C}$ to $25^{\circ} \mathrm{C}$, which lead to a gradual curing of the adhesive. Due to this stiffer behavior of the connection system, it is natural that when damage initiates, its effect is more pronounced, not only in terms of stiffness but also in terms of ultimate load, due to a more abrupt release of the energy accumulated in the constituent materials and bond systems, which justifies the behavior of the last phase of the WD series. 
Fig. 7 presents the failure modes of the specimens after the monotonic tests. The failure occurred only in one of the bonded flanges of the GFRP profile. Although all specimens failed by debonding, the concrete layer peeled off varied with the type of exposure, and thus affecting both the bond stiffness and strength. It is noticeable that at the loaded-end, in the T and WD series, small portions of adhesive remained bonded to the concrete, meaning that cohesive failure occurred. This small portions of cohesive failure denoted that, under such environmental conditions, the adhesive tends to be the weakest component of the system.

In the control specimens the debonding was uniform and the concrete layer peeled off was thicker than the other series (Fig. 7a). This figure also shows the presence of some aggregates in the concrete layer peeled off, denoting the stiffness of the connection.

\subsection{Fatigue behavior}

In Fig. 8, the loaded end slip versus number of cycles at both the maximum and the minimum load levels are plotted for each exposure condition. The shape of the curves is generally similar among the different exposure conditions. Initially, a significant increase of slip is observed up to the 100,000th cycle, which is then followed by a mild growth period where the slip increased slowly until the last cycle. This clearly indicates the continuous degradation of the bond interface during the fatigue load cycles.

Fig. 9 evidences that the amplitude of the loaded-end slip was almost constant during the fatigue loading process, which indicates that the bond connection between GFRP profile and SFRSCC plates was essentially governed by the elastic properties of the adhesive. In the R_F, T_F and WD_F series this amplitude was 14 to $16.5 \mu \mathrm{m}, 26.5$ to $30 \mu \mathrm{m}$ and 16.5 to 20 $\mu \mathrm{m}$, respectively. Therefore, the larger amplitude of loaded-end slip was registered in the T_F series ( $86 \%$ higher than in $\mathrm{R}$ series), which is a consequence of the decrease of the elasticity modulus of the adhesive caused by the exposure conditions that in this series includes a temperature higher than the $\mathrm{Tg}$ of the adhesive. The amplitude of the loaded-slip was $20 \%$ higher in the WD_F series than in R_F series, which was not expected taking into account the stiffest response of the WD series registered in Fig. 6 . The relatively small difference between these two series in terms of loaded-end slip amplitude (it becomes closest during the fatigue loading process) can be justified by the difficulties of assuring equal geometric and material properties for the applied adhesive layer.

\subsection{Post-fatigue monotonic behavior}

After the fatigue tests, all specimens were loaded monotonically up to failure, being the results presented in Fig. 10 and Table 5. Due to the fatigue loading effect, the specimens showed a significant increase in the bond stiffness up to a load range between 50 and $100 \mathrm{kN}$. This phenomenon can be explained by the densest and more compact connection resulted from the fatigue load, promoting a more homogeneous microstructure of all the system (SFRSCC, GFRP and adhesive). Subsequently the specimen starts to reach inexperienced load levels (fatigue loading between 40 and $140 \mathrm{kN}$ ), causing a reduction in the bond stiffness, which remains identical to the results from the monotonic tests.

Thus, the control exposure ( $\mathrm{R}$ series) reached a peak load of approximately $310 \mathrm{kN}$, with a loaded end slip of $32 \mu \mathrm{m}$, presenting a reduction of $1 \%$ and $53 \%$, respectively, when 
compared to the corresponding results registered in the homologous specimens subjected to control exposure and tested in monotonic load conditions. Hence, the fatigue load reduced the ductility of the bond, since the strength remained identical for half of the bond slip.

The specimens subjected to temperature cycles (T series), after the initial "elastic" phase (that ended at about $90 \mathrm{kN}$ ) presented a softer response than the specimens of the $\mathrm{R}$ series. The lower bond stiffness is in agreement with the results from the fatigue behavior for the same specimen, where the slip amplitude was also larger when compared to other series.

The specimens of the WD series, after the initial "elastic" phase (that ended at about $50 \mathrm{kN}$ ), developed a stiffer behavior than the other series, which is in agreement with the results of Fig. 6. The peak load reached $315 \mathrm{kN}$, at a loaded end slip of $30 \mu \mathrm{m}$, which correspond to an increase of $6 \%$ and a reduction of $37 \%$ when compared to the results registered in the specimens subjected to wet-dry cycles and tested under monotonic loading conditions. This behavior is also in agreement with the results obtained in the fatigue tests, where the slip amplitude was smaller than the one determined in the specimen of $\mathrm{T}$ series, which justifies the stiffer bond response of the specimens submitted to WD conditions.

All PF specimens registered a stiffer peak behavior when compared to the homologous specimens submitted to static loading. This behavior is consequence of the test setup adopted, which in the case of the present monotonic tests was slightly different. Thus, in the present test setup the confinement system (see Fig. 4) was kept tighter, to prevent any brittle failure due to the fatigue history of the specimen, leaving only $1 \mathrm{~mm}$ of clearance between the steel member and the concrete plate. Thus, when the passive confinement starts to become active, the system becomes stiffer, leading to a stiffest peak behavior.

Fig. 11 presents the failure modes observed in the specimens that after have been subjected to fatigue loading, were tested under monotonic loading up to failure. Once again, the failure occurred by debonding at the concrete / GFRP flange interface. Moreover, these failure modes were very similar to those registered in the monotonic tests, which means that the failure mode was not affected by the fatigue loading.

\section{Numerical simulations}

A three-dimensional finite element analysis was conducted to predict the bond behavior of the GFRP-concrete adhesive system using the FEMIX 4.0, a software based on the Finite Element Method [18], which includes several types of finite elements and constitutive models for the linear and material nonlinear analysis of cement-based and polymer-based composite materials. The numerical simulation focused only in the control exposure specimens. The following summarizes the numerical approach.

\subsection{Brief description of the Model}

The adopted model, which is described in detail elsewhere [18], is based on the strain decomposition concept for smeared cracked concrete. Herein only a brief description of the model is given in order to provide the fundamental information for an understanding for the data supplied for modeling the behavior of the intervening materials. Based on the above strain decomposition concept, the constitutive law for the cracked concrete has de following format: 


$$
\Delta \underline{\sigma}=\left(\underline{D}^{c o}-\underline{D}^{c o}\left[\underline{T}^{c r}\right]^{T}\left(\underline{D}^{c r}+\underline{T}^{c r} \underline{D}^{c o}\left[\underline{T}^{c r}\right]^{T}\right)^{-1} \underline{T}^{c r} \underline{D}^{c o}\right) \Delta \underline{\varepsilon}
$$

where $\underline{D}^{c o}$ is the elasticity matrix for concrete between cracks that depends on the Young's modulus $(E)$ and the Poisson's ratio $(v)$ of this material, $\underline{T}^{c r}$ is the transformation matrix that transforms the stress components from the global coordinate system to the local crack coordinate system $\left(n, t_{1}\right.$ and $t_{2}$ axes, where $n$ is the vector orthogonal to the crack plane, while $t_{1}$ and $t_{2}$ are in crack plane). In Eq. (1) $\underline{D}^{c r}$ is the crack constitutive matrix:

$$
\underline{D}^{c r}=\left[\begin{array}{ccc}
D_{n}^{c r} & 0 & 0 \\
0 & D_{t_{1}}^{c r} & 0 \\
0 & 0 & D_{t_{2}}^{c r}
\end{array}\right]
$$

where $D_{n}^{c r}, D_{t_{1}}^{c r}$ and $D_{t_{2}}^{c r}$ represent, respectively, the fracture mode I softening modulus, and the sliding softening modulus in the $\hat{t}_{1}$ and $\hat{t}_{2}$ direction. The fracture mode I modulus, $D_{n}^{c r}$, is defined by the tensile-softening diagram represented in Fig. 12, while the sliding fracture mode modulus, $D_{t_{1}}^{c r}$ or $D_{t_{2}}^{c r}$, can be obtained with,

$$
D_{t_{1}}^{c r}=D_{t_{2}}^{c r}=\frac{\beta}{1-\beta} G_{c}
$$

where $G_{c}$ is the concrete elastic shear modulus and $\beta$ is the shear retention factor:

$$
\beta=\left(1-\frac{\varepsilon_{n}^{c r}}{\varepsilon_{n, u}^{c r}}\right)^{p_{1}}
$$

where $\varepsilon_{n}^{c r}$ is the current crack normal strain and $\varepsilon_{n, u}^{c r}$ is the ultimate crack normal strain. Alternatively, to model the crack shear stress transfer in $\hat{t}_{1}$ and $\hat{t}_{2}$ directions, and to improve the accuracy of the simulations of structures failing in shear, $D_{t_{1}}^{c r}$ or $D_{t_{2}}^{c r}$ can be obtained with an independent shear crack softening diagram [18].

\subsection{Mesh, loading, boundary conditions and constitutive models}

Fig. 13 shows the FE mesh geometry adopted in the numerical simulations. As the specimens used are symmetric along the $\mathrm{x} 1$ and $\mathrm{x} 2$ axis, only one fourth of the specimen was simulated. A relative mesh fine refinement was used with a maximum element size of $25 \mathrm{~mm}$. The boundary conditions were applied to simulate the test conditions (see Fig. 4), by constraining necessary nodes in translation at supports of the specimens. The load was applied uniformly along the upper edge of the GFRP profile in agreement with the test procedure.

Four different constitutive models were used in the simulation of the different components composing the system. All three materials, concrete, adhesive and GFRP, were modeled using 20-node solid finite elements with $2 \times 2 \times 2$ Gauss-Legendre integration scheme. Only one layer of solid elements was used in the adhesive. Perfect bond was assumed 
between all the elements. The GFRP profiles were modeled assuming linear and isotropic behavior material, characterized by a Young's modulus of $34 \mathrm{GPa}$ and a Poison's ratio of 0.18 (IV, Fig. 13). The concrete was separated in two layers, one assuming linear material behavior (I) and the other assuming nonlinear material behavior (II). The thickness of the nonlinear material behavior layer was determined from concrete layer peeled off from the experimental results. Hence, the thickness used was $5 \mathrm{~mm}$, which is greater than those from the experimental results. The linear material behavior for concrete is characterized by a Young's modulus of $32 \mathrm{GPa}$ and a Poisson's ratio of 0.20 (I, Fig. 13). The 3D multi-fixed smeared crack model briefly described in the previous section was adopted to simulate the nonlinear material simulation of concrete and adhesive [18]. Table 6 shows the values of the model parameters used in the simulations. The trilinear tensile diagram represented in Fig. 12 was used for modeling the fracture mode I in both the concrete and adhesive. However, the concrete was assumed a tensile strain softening material, while adhesive a tensile strain hardening material (see the values in Table 6 that define the trilinear diagram). A maximum of 2 cracks per integration point was adopted, being the crack bandwidth the square root of the integration point. In the present simulations a value of 2 was assumed for the $p_{1}$ parameter in Eq. (4). The parameters of the concrete and adhesive were obtained in previous experimental programs dedicated to the characterization of the SFRSCC and epoxy adhesive $[15,19]$. For modeling the tensile nonlinear behavior of the adhesive observed in experimental tensile tests [14], the 3D smeared crack model described in Section 4.1 was used, by considering that the inelastic tensile deformation is caused by the formation of diffuse micro-cracks in its micro-structure, thereby being considered as a strain-hardening material governed by the fracture properties indicated in Table 6. This approach was already adopted with success by Costa and Barros [15]. The smaller elasticity modulus adopted in the numerical simulation for the adhesive simulates the higher deformability that the adhesive presents in the SFRSCC-GFRP connection (when compared to the deformability determined in samples prepared in laboratory and tested in idealized tensile conditions) due to the higher susceptibility of introducing voids and defects in the adhesive layer during its application process. These values were obtained by inverse analysis, by fitting as closest as possible the experimental results.

\subsection{Results}

\subsubsection{Relative displacements}

Fig. 14 shows the points where the measurements were made, in both numerical and experimental procedures. Regarding the relative displacement between the concrete and the GFRP profile, these measurements were made in the experimental tests along the bond length in four different points, as mentioned in Section 2.2. These points (A to D) are equally spaced by $87.5 \mathrm{~mm}$ (LVDT's 1 to 5 in Fig. 3). The results presented in this section were compared with a control specimen (R series) under monotonic load.

Fig. 15 shows the results, for the relative displacement between the GFRP flange and the concrete, comparing both the numerical and experimental results, in the four different points (A to D). The trends of the numerical results compared well with those from the experimental results. Thus, as expected, the results show a decrease in the relative displacement as the distance from the loaded-end increases. Hence, in point $\mathrm{D}$ the relative displacement reaches only $16 \%$ of the loaded-end slip (point A). The brittle failure of the bond can be explained by its high stiffness, as shown by the very small relative displacements measured. 


\subsubsection{Stresses and failure modes}

Fig. 16 shows the relationship between the applied force and stresses in both materials, concrete and GFRP ( $\mathrm{x}_{3}$ direction). In the experimental tests, the strain was measured using strain gages. Then, the Hooke's law was used to convert the strains in stresses. This assumption for the concrete is acceptable since the level of stress state in the analyzed region was quite low when compared with the compressive strength of the concrete. On the other hand, GFRP material is assumed to be linear elastic up to the failure.

The compressive stress measured in concrete (point E) shows a nonlinear behavior up to $240 \mathrm{kN}$. This behavior is explained by the degradation of the bond stiffness. As the micro cracking grows, the load transfer between the adhesive and the concrete starts to decrease, causing a slightly reduction in the concrete stress in point $\mathrm{E}$. Then, before failure, the micro cracking growths causing macro-cracks in concrete, resulting in the debonding of the adhesive. This local debonding causes a great reduction in the load transfer between the adhesive and the concrete, resulting in a reduction of stresses in concrete from $240 \mathrm{kN}$ up to failure. In point $\mathrm{F}$, near the supports zone, the compressive stress is higher and present a linear response, as expected, reaching $9 \mathrm{MPa}$.

The compressive stress measured in the GFRP profile in point G (see Fig. 16) also exhibits a linear behavior up to $240 \mathrm{kN}$. After the $240 \mathrm{kN}$ load, the stress increases significantly. This increase is caused by the reduction in the load transfer between the adhesive and the concrete, i.e., as the connection starts to debond, the load starts to be transferred to the profile, causing an increase in the compressive stress in the GFRP, and a reduction in the compressive stress in the concrete.

The crack pattern presented in Fig. 17, regarding the cracks in the concrete, illustrates the phenomena described previously. It is noticeable that at a load of $150 \mathrm{kN}$ a significant number of cracks occurred in the loaded-end zone, that significantly increase up to a load of $240 \mathrm{kN}$, causing an increase in the compressive stress in the GFRP profile (point G) along with a reduction in the compressive stress in the concrete (point E). At a load of $200 \mathrm{kN}$ the cracks start to appear along the bond length, increasing up to the load of $240 \mathrm{kN}$. Thus, the bond surface starts to be filled with cracks, weakening the connection and leading to the failure of the system. Regarding the adhesive, only few micro cracks occurred, which did not contributed to the system failure.

\section{Conclusions}

The performance under static, fatigue and aggressive exposure of the proposed adhesive joints was investigated experimentally. Based on the results of the investigations presented in this paper, the following conclusions can be pointed out:

- The results from the monotonic tests evidenced that when the connection is exposed to the temperature cycles ( $\mathrm{T}$ series) a reduction of $41 \%$ in the peak load was obtained, when compared to the control exposure ( $\mathrm{R}$ series), indicating that the detrimental effect of the temperature cycles should be considered on the design evaluation of the long term performance of this type of connection.

- The failure modes for the monotonic tests showed that all specimens failed by debonding. However, the area of the concrete layer peeled off has varied with the type of exposure, and thus affecting the bond stiffness and strength of the connection. For 
the $\mathrm{T}$ and WD series, in some portions of the bonded area, cohesive failure of the adhesive occurred due to the aggressive exposure, being more pronounced in the WD series.

- The fatigue behavior showed a slightly continuous degradation of the bond interface during the fatigue load cycles. These results also revealed that during the fatigue loading the specimens from the WD series presented a less stiff response, since the slip amplitude was larger than those of the reference specimens. Moreover, from the maximum and the minimum slip curves, it is noticeable that the stiffness remained constant during the fatigue loading for the three series. After 1 million cycles, the specimens did not display any visible damage.

- The post-fatigue monotonic behavior was affected by the fatigue loading, i.e., in terms of initial stiffness the fatigue loading had a favorable effect of increasing significantly bond stiffness up to a load interval between 50 and $100 \mathrm{kN}$. Then, when the monotonic load level applied to the specimen exceeded the maximum load level the specimen has experienced in the fatigue loading process, a significant reduction in the bond stiffness has occurred, becoming identical to the stiffness registered in the monotonic tests.

- By simulating a representative push-out test of a specimen of the $\mathrm{R}$ series subjected to monotonic loading, it was verified that by using a 3D smeared crack model for modeling the material nonlinear behavior of SFRSCC and adhesive, and assuming the GFRP profile as formed by a linear and elastic material, the relevant results obtained experimentally were predicted accurately.

\section{Acknowledgements}

This research is part of the research project funded by ADI co-financing FEDER by POFC - COMPETE of QREN No 3456 - PONTALUMIS Development of a prototype of a pedestrian bridge in GFRP-ECC concept, involving the Company ALTO - Perfis Pultrudidos, Lda., the ISISE/University of Minho and the ICIST/Technical University of Lisbon. The first author wish to acknowledge the research grant under this project. The authors also wish to acknowledge the Civitest Company for the conception and development of the steel fiber reinforced self-compacting concrete used in this work, to Secil and S\&P Clever Reinforcement Ibérica, Lda. for the supplied materials and technical support.

\section{References}

1. Bank LC. Composites for Construction: structural design wiyh FRP materials. Polymer. Hoboken, NJ: JOHN WILEY \& SONS, 2006.

2. Bakis CE, Bank LC, Brown VL, Cosenza E, Davalos JF, Lesko JJ, et al. Fiberreinforced polymer composites for construction-state-of-the-art review. Journal of Composites for Construction, 2002; 6(2):73-87.

3. Hayes MD, Lesko JJ, Haramis J, Cousins TE, Gomez J, Masarelli P. Laboratory and Field Testing of Composite Bridge Superstructure. Journal of Composites for Construction, 2000;4(3):120-8. 
4. Keller T. Use of fibre reinforced polymers in bridge construction. International association for bridge and structural engineering. Zurich: IABSE-AIPC-IVBH, 2003.

5. Mendes PJD, Barros JAO, Sena-Cruz JM, Taheri M. Development of a pedestrian bridge with GFRP profiles and fiber reinforced self-compacting concrete deck. Composite Structures, 2011;93(11):2969-82.

6. Hejll A, Täljsten B, Motavalli M. Large scale hybrid FRP composite girders for use in bridge structures-theory, test and field application. Composites Part B: Engineering, 2005; 36(8):573-85.

7. Täljsten B. Construction of the asset polymer composite bridge. Asia-Pacific Conference on FRP in Structures (APFIS 2007), 12-14 December 2007, Hong Kong, China, 6 pp.

8. Chiu A, Franco RJ. FRP line pipe for oil and gas production. Mod Plast 1990; June:5460 .

9. Pereira ENB. Steel fibre reinforced self-compacting concrete: from material to mechanical behaviour. Dissertation for pedagogical and scientific aptitude proofs. Department of Civil Engineering, University of Minho; 2006. 188 pp. <http://www.civil.uminho.pt/composites>.

10. EFNARC, Specification and Guidelines for Self-Compacting Concrete (2002), ISBN, 0 95397334 4, 32 pp.

11. Correia JR, Branco FA, Ferreira JG. Structural Behaviour of GFRP-Concrete hybrid beams. Composites in Construction - Third International Conference, Lyon, France, 11-13 July 2005. 8 pp.

12. Correia MM, Nunes F, Correia JR, Silvestre N. Buckling Behavior and Failure of Hybrid Fiber-Reinforced Polymer Pultruded Short Columns. Journal of Composites for Construction, 2013;17(4):463-475.

13. ISO 527-2:1993. "Plastics - Determination of tensile properties - Part 2: Test conditions for moulding and extrusion plastics." International Organization for Standardization - ISO, Genève, 8 pp.

14. Sena-Cruz JM, Michels J, Czaderski C, Motavalli M. Mechanical behavior of epoxy adhesives cured at high temperatures. Report no. 880163, Empa - Swiss Federal Laboratories for Materials Science and Technology, Switzerland, 2012. 40 pp.

15 Costa IG, Barros JAO. Assessment of the long term behaviour of structural adhesives in the context of NSM flexural strengthening technique with prestressed CFRP laminates. FRPRCS11, Guimarães, Portugal, 26-28 June 2013.

16. Portuguese Weather Institute. Annual Climatologic Boletim - 2011 Relevant Climate Facts and Phenomena in 2011. Lisbon; 2011. 
17. Moussa O, Vassilopoulos AP, De Castro J, Keller T. Early-age tensile properties of structural epoxy adhesives subjected to low-temperature curing. International Journal of Adhesion and Adhesives, 2012; 35:9-16.

18. Ventura-Gouveia A. Constitutive models for the material nonlinear analysis of concrete structures including time dependent effects. PhD Thesis, Department of Civil Engineering, University of Minho, 2011.

19. Häßler D, Barros JAO. Exploring the possibilities of steel fibre reinforced selfcompacting concrete for the flexural strengthening of masonry structural elements. International Journal of Architectural Heritage Conservation, Analysis, and Restoration, 2012; 7(1):26-53.

\section{List of Tables}

Table 1 - SFRSCC mix proportion per m3

Table 2 - (a) Rheological and (b) mechanical properties of the SFRSCC.

Table 3 - Main mechanical properties of the GFRP profile [12].

Table 4 - Specimens and test program

Table 5 - Monotonic and post-fatigue test results.

Table 6 - Concrete and adhesive properties used in the numerical simulation (see Fig. 13). 
Table 1 - SFRSCC mix proportion per $\mathrm{m}^{3}$

\begin{tabular}{cccccccc}
\hline $\begin{array}{c}\text { Cement } \\
{[\mathrm{kg}]}\end{array}$ & $\begin{array}{c}\text { Limestone } \\
\text { filler }[\mathrm{kg}]\end{array}$ & $\begin{array}{c}\text { Water } \\
{[\mathrm{kg}]}\end{array}$ & $\begin{array}{c}\text { Superplasticizer } \\
{[\mathrm{kg}]}\end{array}$ & $\begin{array}{c}\text { Fine sand } \\
{[\mathrm{kg}]}\end{array}$ & $\begin{array}{c}\text { River } \\
\text { sand } \\
{[\mathrm{kg}]}\end{array}$ & $\begin{array}{c}\text { Crushed } \\
\text { stone } \\
{[\mathrm{kg}]}\end{array}$ & $\begin{array}{c}\text { Fibers } \\
{[\mathrm{kg}]}\end{array}$ \\
\hline 380.54 & 353.00 & 140.00 & 7.83 & 237.00 & 710.00 & 590.00 & 60.00 \\
\hline
\end{tabular}

Table 2 - (a) Rheological and (b) mechanical properties of the SFRSCC.

(a)

\begin{tabular}{cc}
\hline Parameter & Value \\
\hline Slump flow & Diameter $=80 \mathrm{~cm}$ \\
V-funnel & $\mathrm{T} 50=4 \mathrm{~s}$ \\
L-box & $\mathrm{T}=9 \mathrm{~s}$ \\
$\mathrm{H} 2 / \mathrm{H} 1=0.8$ \\
\hline
\end{tabular}

(b)

\begin{tabular}{ccccccccc}
\hline $\begin{array}{c}\text { Compressive } \\
\text { strength } \\
{[\mathrm{MPa}]}\end{array}$ & $\begin{array}{c}\text { Young's } \\
\text { modulus } \\
{[\mathrm{GPa}]}\end{array}$ & $\begin{array}{c}\text { Flexural } \\
\text { tensile } \\
\text { strength } \\
{[\mathrm{MPa}]}\end{array}$ & $\begin{array}{c}\mathrm{f}_{\mathrm{R}, 1} \\
{[\mathrm{MPa}]}\end{array}$ & $\begin{array}{c}\mathrm{f}_{\mathrm{R}, 2} \\
{[\mathrm{MPa}]}\end{array}$ & $\begin{array}{c}\mathrm{f}_{\mathrm{R}, 3} \\
{[\mathrm{MPa}]}\end{array}$ & $\begin{array}{c}\mathrm{f}_{\mathrm{R}, 4} \\
{[\mathrm{MPa}]}\end{array}$ & $\begin{array}{c}\mathrm{f}_{\mathrm{eq}, 2} \\
{[\mathrm{MPa}]}\end{array}$ & $\begin{array}{c}\mathrm{f}_{\mathrm{eq}, 3} \\
{[\mathrm{MPa}]}\end{array}$ \\
\hline 47.00 & 32.00 & 10.20 & 9.15 & 11.34 & 9.08 & 7.54 & 9.06 & 9.85 \\
\hline
\end{tabular}

Table 3 - Main mechanical properties of the GFRP profile [12]

\begin{tabular}{|c|c|c|c|c|c|c|}
\hline \multirow[t]{2}{*}{$\begin{array}{l}\text { GFRP } \\
\text { profile }\end{array}$} & \multicolumn{2}{|c|}{$\begin{array}{l}\text { Tension (longitudinal } \\
\text { direction) }\end{array}$} & \multicolumn{2}{|c|}{$\begin{array}{c}\text { Compression (longitudinal } \\
\text { direction) }\end{array}$} & \multicolumn{2}{|c|}{$\begin{array}{c}\text { Compression (transverse } \\
\text { direction) }\end{array}$} \\
\hline & $\sigma_{\mathrm{tu}, \mathrm{L}}[\mathrm{MPa}]$ & $\mathrm{E}_{\mathrm{t}, \mathrm{L}}[\mathrm{GPa}]$ & $\sigma_{\mathrm{cu}, \mathrm{L}}[\mathrm{MPa}]$ & $\mathrm{E}_{\mathrm{c}, \mathrm{L}}[\mathrm{GPa}]$ & $\sigma_{\mathrm{cu}, \mathrm{T}}[\mathrm{MPa}]$ & $\mathrm{E}_{\mathrm{c}, \mathrm{T}}[\mathrm{GPa}]$ \\
\hline Webs & $385.3 \pm 23.7$ & $33.0 \pm 1.2$ & $460.4 \pm 64.4$ & $26.7 \pm 1.2$ & $106.1 \pm 28.5$ & $7.67 \pm 2.0$ \\
\hline Flange & $414.2 \pm 21.0$ & $35.9 \pm 2.1$ & $388.6 \pm 59.2$ & $33.9 \pm 3.4$ & $70.4 \pm 17.4$ & $5.9 \pm 0.6$ \\
\hline
\end{tabular}

Notes: $\sigma_{\mathrm{tu}, \mathrm{L}}=$ ultimate tensile strength in the longitudinal direction; $\mathrm{E}_{\mathrm{t}, \mathrm{L}}=$ tensile Young's modulus in the longitudinal direction; $\sigma_{\mathrm{cu}, \mathrm{L}}=$ ultimate compression strength in the longitudinal direction; $\mathrm{E}_{\mathrm{c}, \mathrm{L}}=$ compression Young's modulus in the longitudinal direction; $\sigma_{\mathrm{cu}, \mathrm{T}}=$ ultimate compression strength in the transverse direction; $\mathrm{E}_{\mathrm{c}, \mathrm{T}}=$ compression Young's modulus in the transverse direction. 
Table 4-Specimens and test program

\begin{tabular}{lll}
\hline Exposure regime & Duration & No. of specimens \\
\hline Wet-dry & 100 cycles (one cycle $=1$ day) & 6 \\
Temperature cycle & 100 cycles (one cycle $=4$ hours) & 6 \\
Control & 3 months & 6
\end{tabular}

Table 5 - Monotonic and post-fatigue test results.

\begin{tabular}{|c|c|c|c|c|c|c|}
\hline $\begin{array}{l}\text { Specimen } \\
\text { ID }\end{array}$ & $\begin{array}{l}\text { Peak load } \\
(\mathrm{kN})\end{array}$ & Average (CoV \%) & $\begin{array}{l}\text { Strength } \\
\text { ratio }(\%)\end{array}$ & $\begin{array}{c}\text { Max slip } \\
(\mu \mathrm{m})\end{array}$ & Average $(\mathrm{CoV} \%)$ & $\begin{array}{c}\text { Slip ratio } \\
(\%)\end{array}$ \\
\hline R_S1 & 220.5 & & & 64.0 & & \\
\hline R_S2 & 314.7 & $284.0(19.3)$ & 100 & 69.2 & $60.7(17.2)$ & 100 \\
\hline R_S3 & 317.0 & & & 49.0 & & \\
\hline T_S1 & 208.0 & & & 65.7 & & \\
\hline T_S2 & 192.0 & $194.3(6.5)$ & 68.4 & 30.7 & $46.1(38.8)$ & 76.0 \\
\hline T_S3 & 183.0 & & & 41.8 & & \\
\hline WD_S1 & 296.2 & & & 48.3 & & \\
\hline WD_S2 & 294.0 & $283.3(7.2)$ & 99.8 & 52.7 & $51.9(6.2)$ & 85.5 \\
\hline WD_S3 & 259.6 & & & 54.6 & & \\
\hline R_PF1 & 333.0 & & & 10.0 & & \\
\hline R_PF2 & 333.0 & $325.3(4.1)$ & 115.0 & 16.3 & $19.5(59.0)$ & 32.1 \\
\hline R_PF3 & 310.0 & & & 32.4 & & \\
\hline T_PF1 & 241.0 & & & 43.8 & & \\
\hline T_PF2 & 298.0 & $257.3(13.8)$ & 90.6 & 14.0 & $24.3(69.7)$ & 40.0 \\
\hline T_PF3 & 233.0 & & & 15.0 & & \\
\hline WD_PF1 & 222.0 & & & 10.0 & & \\
\hline WD_PF2 & 226.0 & $254.3(20.8)$ & 89.5 & 28.0 & $23.0(49.4)$ & 37.9 \\
\hline WD_PF3 & 315.0 & & & 31.0 & & \\
\hline
\end{tabular}


Table 6-Concrete and adhesive properties used in the numerical simulation (see [18]).

\begin{tabular}{|c|c|c|c|}
\hline \multirow{2}{*}{ Parameter } & \multirow{2}{*}{ Unit } & \multicolumn{2}{|c|}{ Value } \\
\cline { 2 - 4 } & & Concrete (II) & Adhesive (III) \\
\hline Young's modulus & $\mathrm{GPa}$ & 32.0 & 4.5 \\
\hline Compressive strength & $\mathrm{MPa}$ & 47.0 & 6.4 \\
\hline Tensile strength & $\mathrm{MPa}$ & 2.3 & 0.2 \\
\hline Fracture energy $\left(G_{f}^{I}\right)$ & $\mathrm{N} / \mathrm{m}$ & 2.9 & 2.5 \\
\hline$\alpha_{1}{ }^{*}$ & - & 0.5 & 0.06 \\
\hline$\alpha_{2}{ }^{*}$ & - & 0.2 & 0.14 \\
\hline$\xi_{1}^{*}$ & - & 0.05 & 30 \\
\hline$\xi_{2}^{*}$ & - & 0.5 & 30 \\
\hline Threshold angle & & & \\
\hline
\end{tabular}

${ }^{*}\left(\alpha_{1}=\sigma_{n, 2}^{c r} / \sigma_{n, 1}^{c r}, \alpha_{2}=\sigma_{n, 3}^{c r} / \sigma_{n, 1}^{c r}, \xi_{1}=\varepsilon_{n, 2}^{c r} / \varepsilon_{n, u}^{c r}, \xi_{2}=\varepsilon_{n, 3}^{c r} / \varepsilon_{n, u}^{c r}\right)$

\section{List of Figures}

Fig. 1 - Bridge concept.

Fig. 2 - Connection configuration.

Fig. 3 - Geometry of the tested specimens (dimensions in $\mathrm{mm}$ )

Fig. 4 - Test apparatus. 1

Fig. 5 - Time-temperature curve imposed in the temperature cycle exposure.

Fig. 6 - Typical load versus loaded slip curves of monotonic tests (specimens R_S2, T_S3 and WD_S1).

Fig. 7 - Failure modes observed in the monotonic tests of series: (a) R; (b) T, and (c) WD.

Fig. 8 - Slip versus number of cycle of the three different exposures under fatigue loading (specimens R_F3, T_F1 and WD_F3).

Fig. 9 - Slip amplitude for the three different exposures (specimens R_F3, T_F1 and WD_F3).

Fig. 10 - Load slip curves of the post-fatigue tests.

Fig. 11 - Failure modes for the post-fatigue monotonic tests in specimens of series: (a) R; (b) $\mathrm{T}$, and (c) WD.

Fig. 12 - Trilinear tensile diagram. 
Fig. 13 - Constitutive models used in the numerical simulation.

Fig. 14 - Points monitored.

Fig. 15 - Comparison between numerical and experimental results in terms of relative displacement versus along the bond length (see also Fig. 14).

Fig. 16 - Comparison between numerical and experimental results in terms of load versus stresses measured in the points $\mathrm{E}$ to $\mathrm{H}$ (see also Fig. 14).

Fig. 17 - Crack pattern for a load level of (a) for $150 \mathrm{kN}$, (b) $200 \mathrm{kN}$ and (c) $240 \mathrm{kN}$; (d) 240 $\mathrm{kN}$ experimental
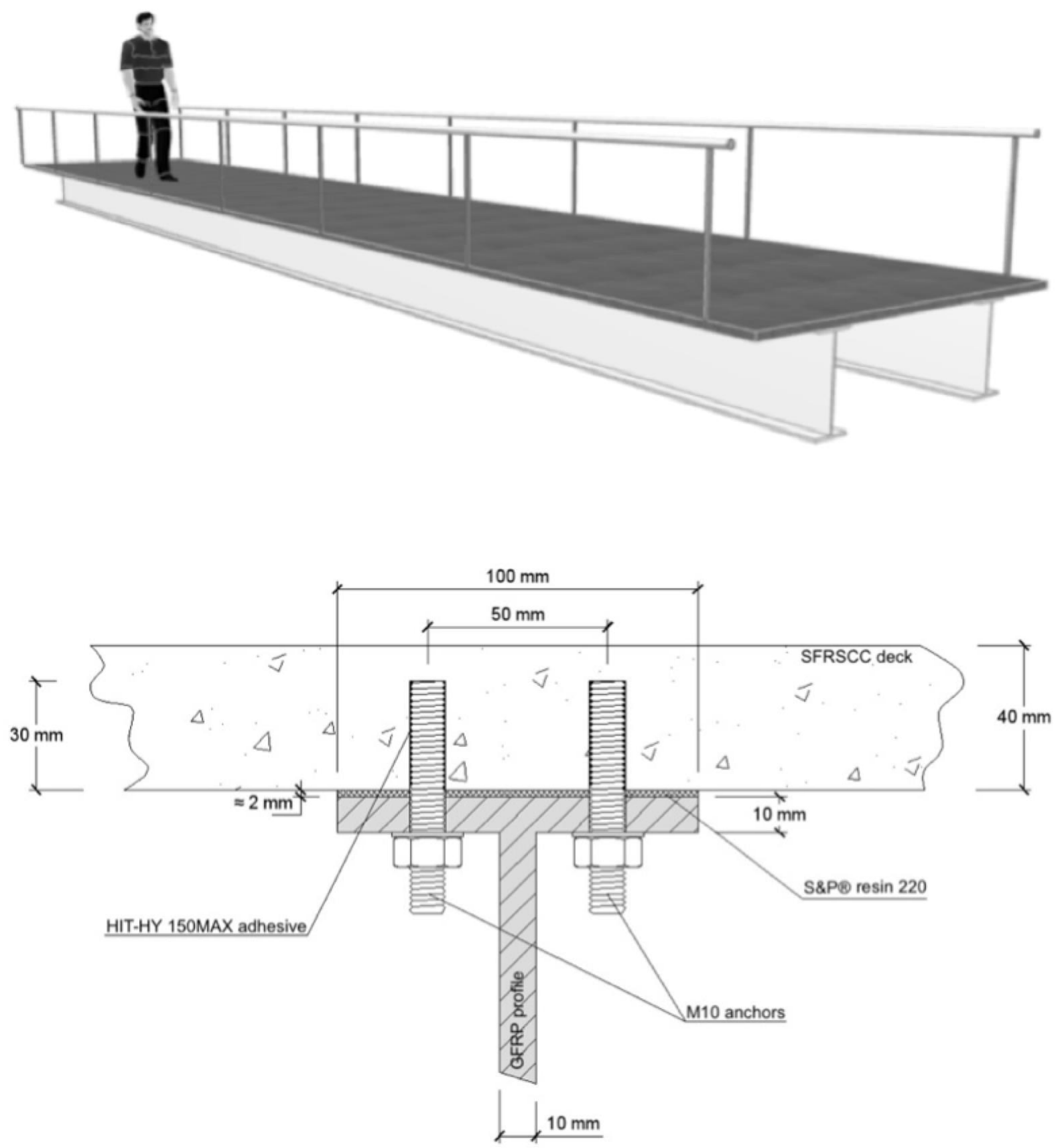


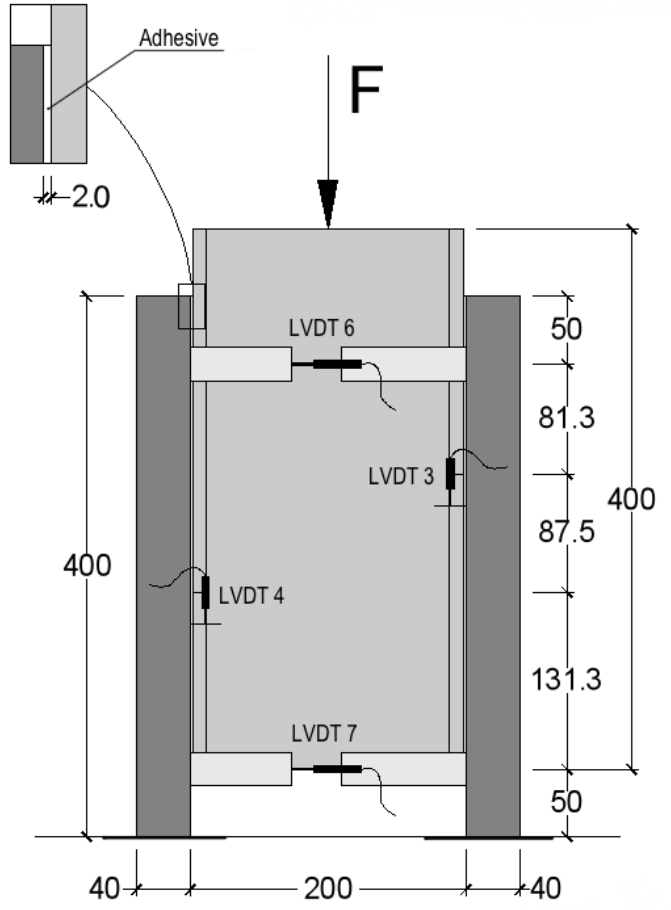

Front view

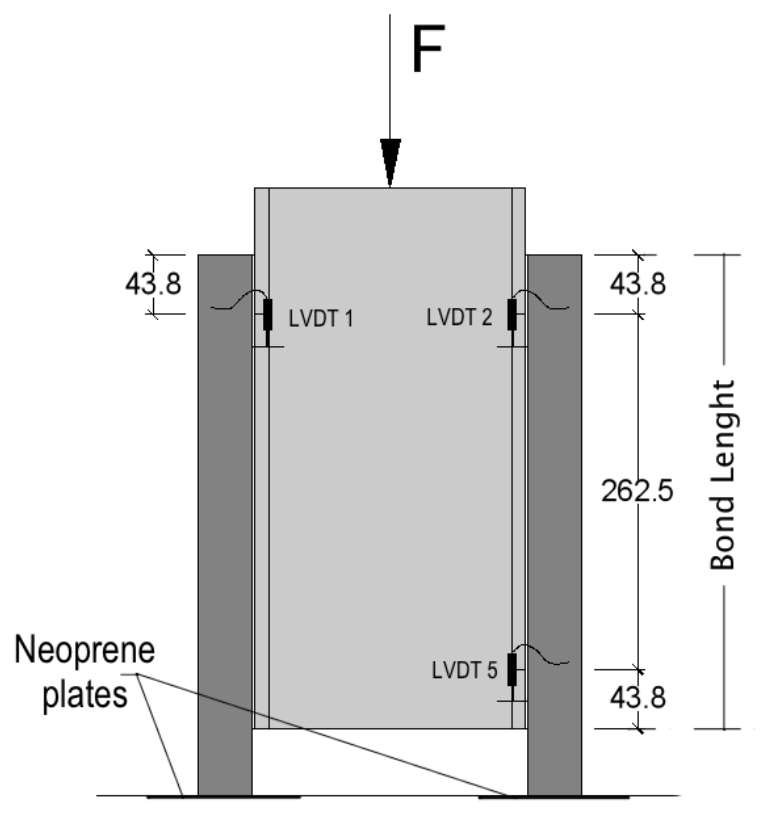

Back view 


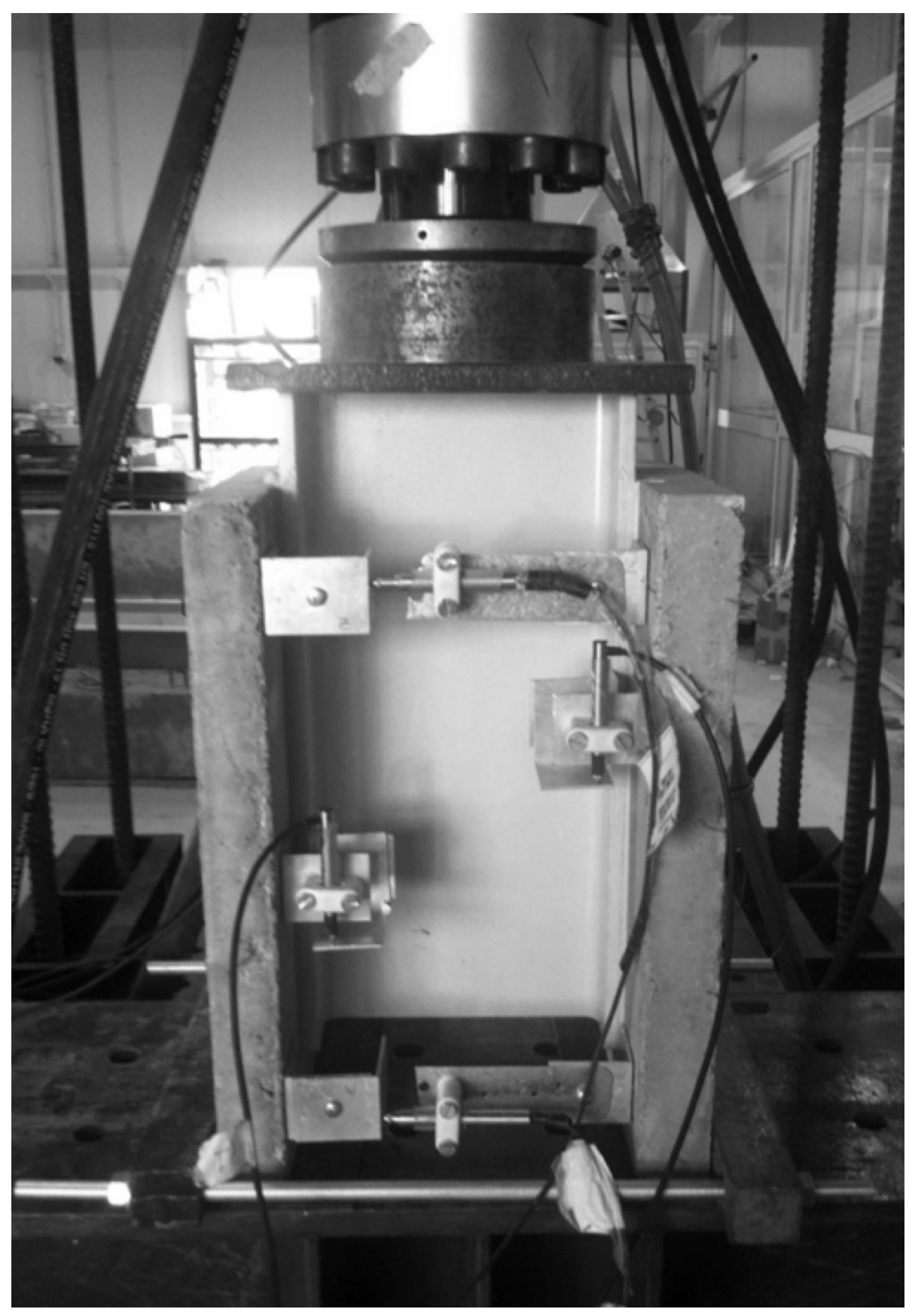




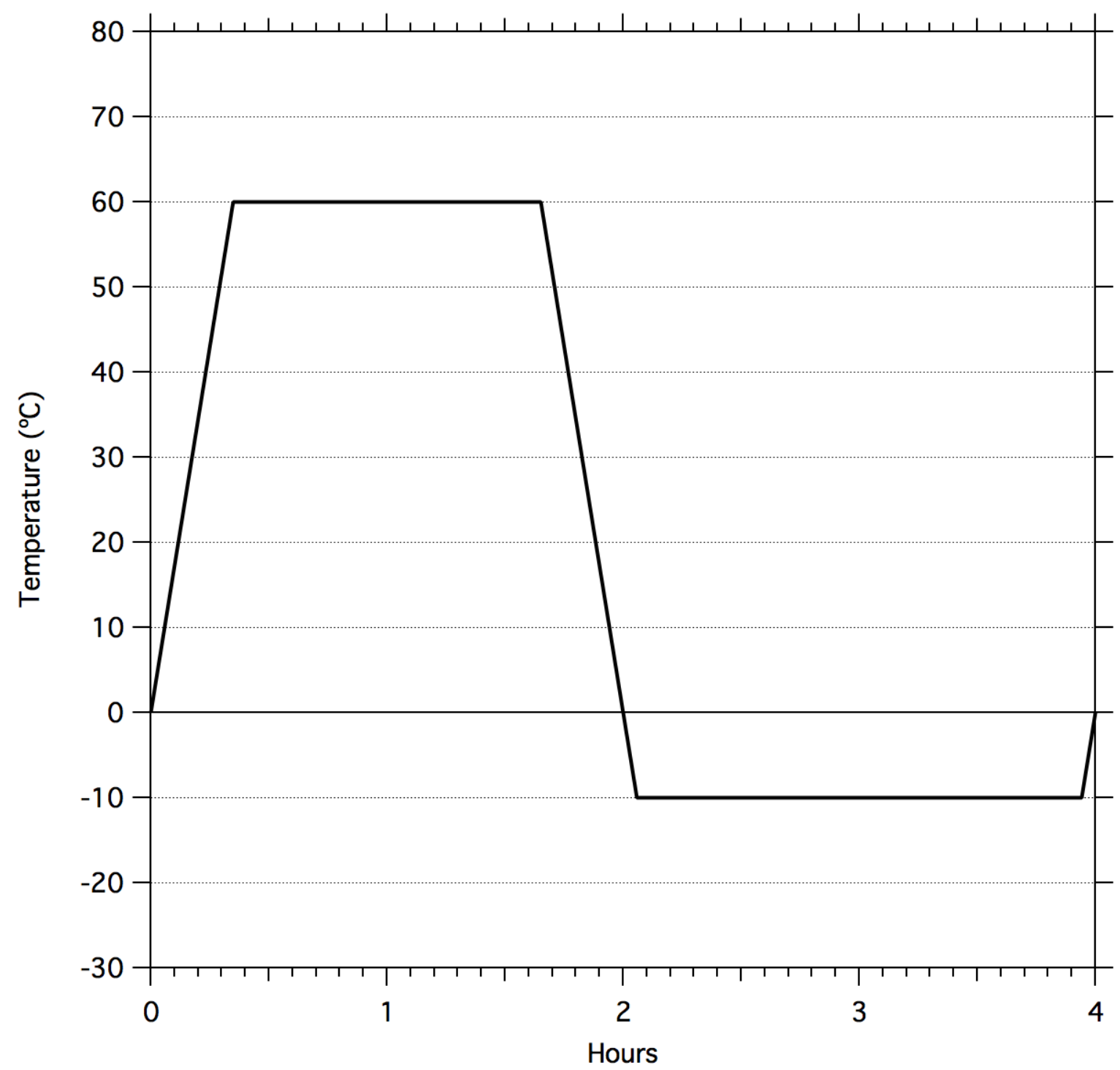




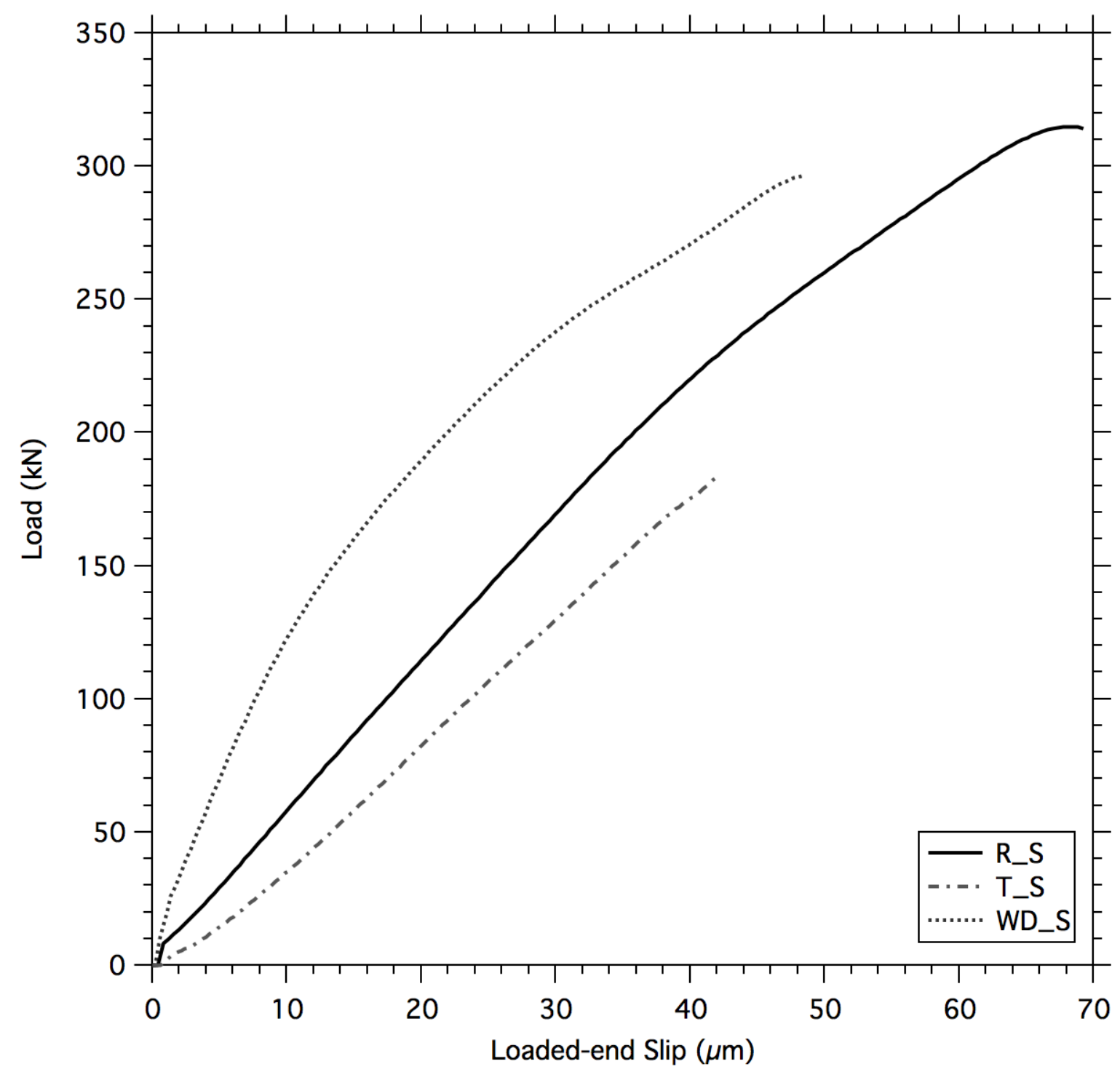

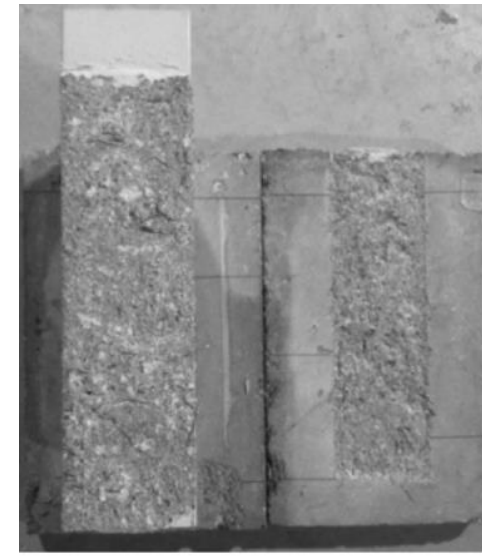

(a)

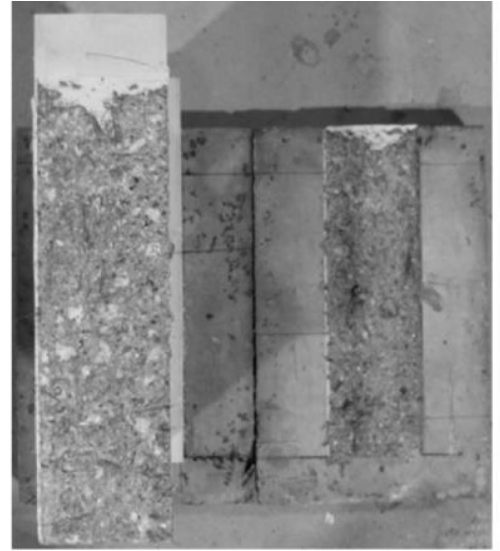

(b)

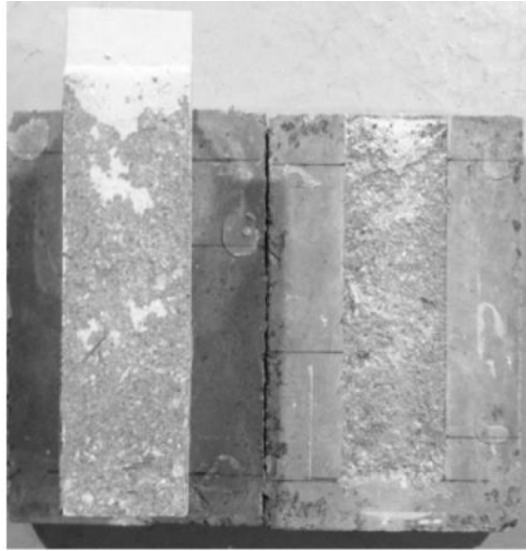

(c) 


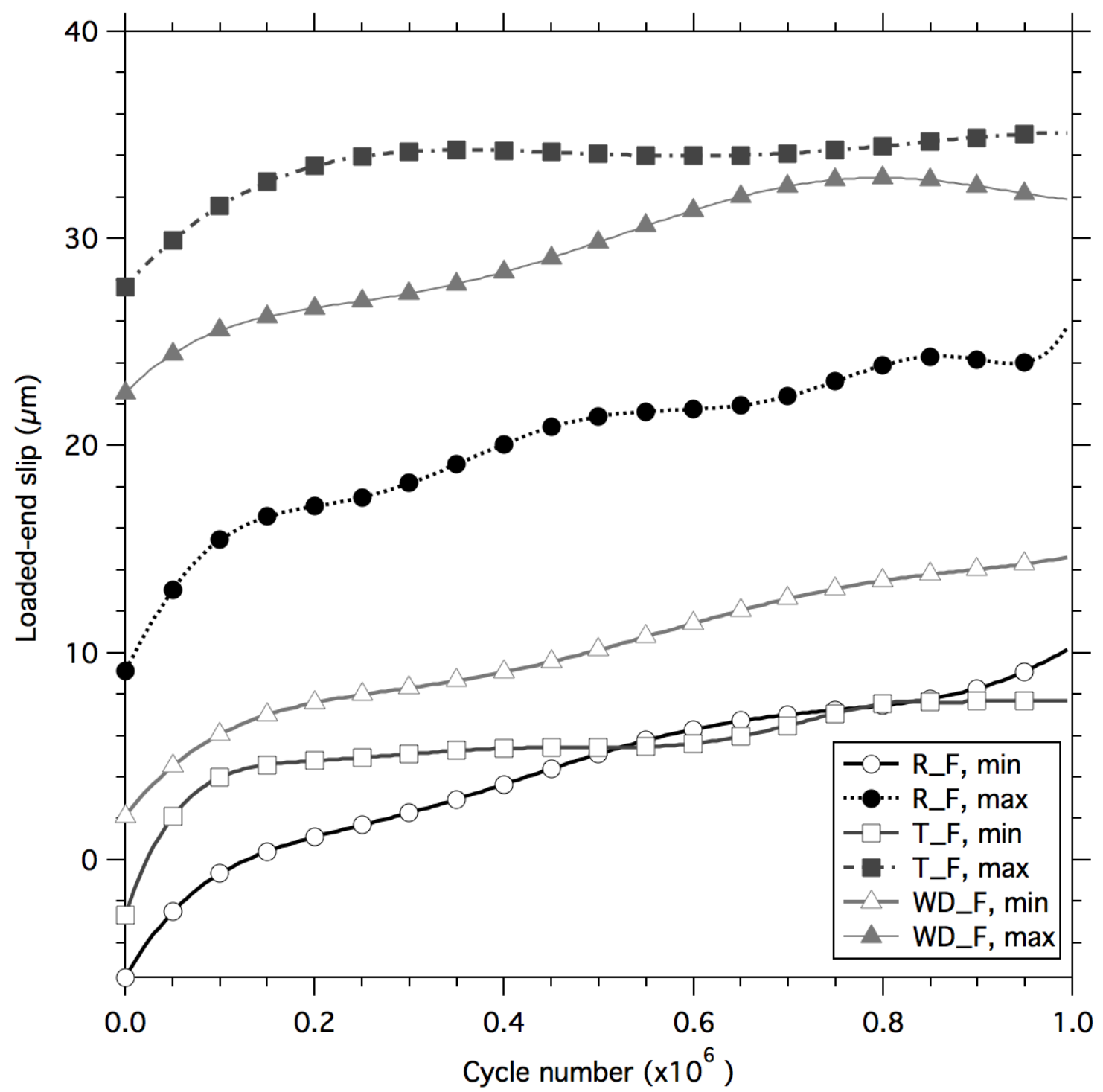




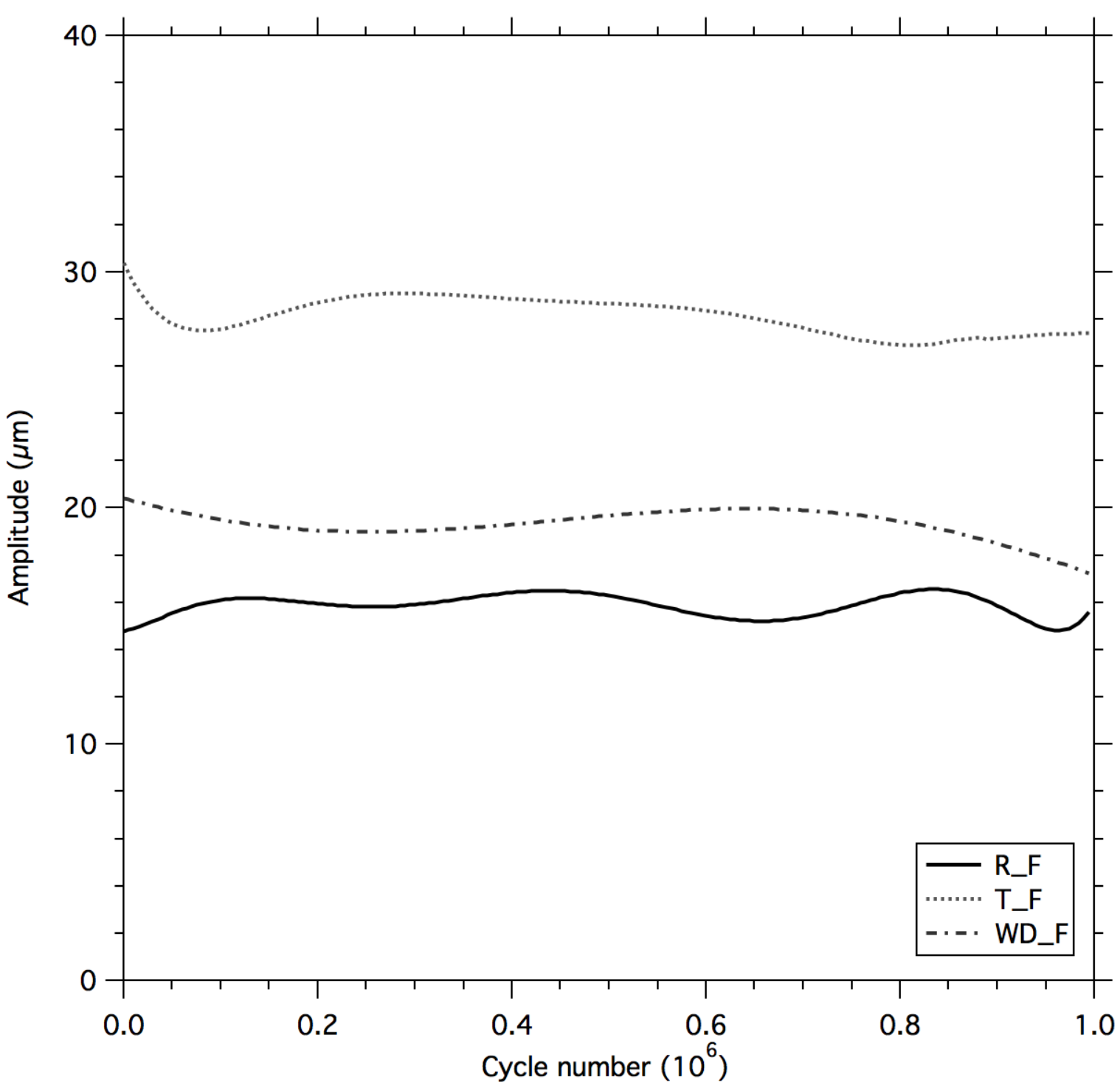




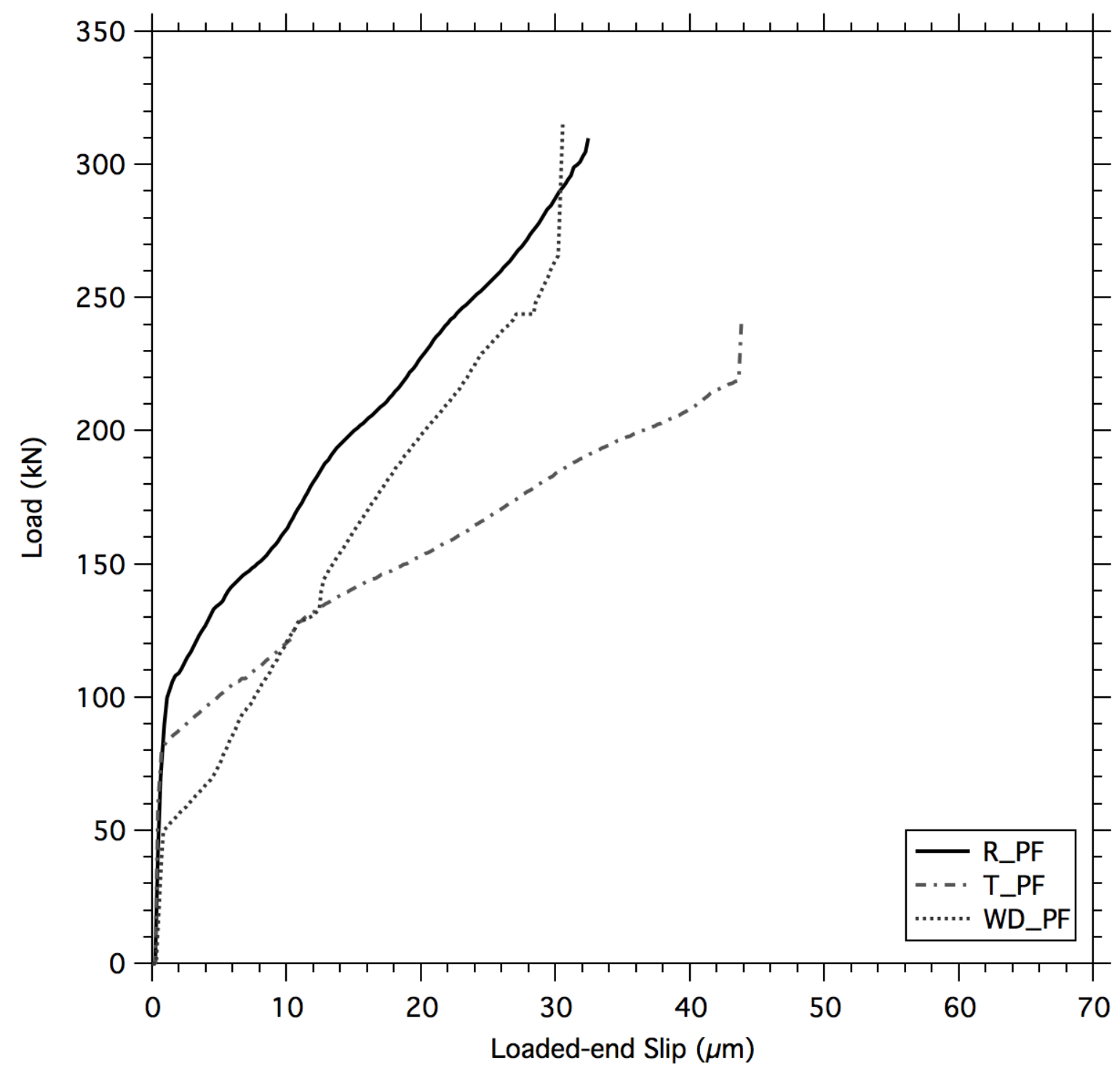

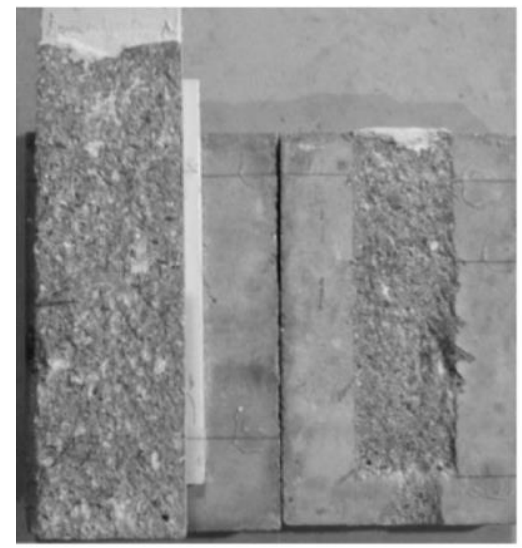

(a)

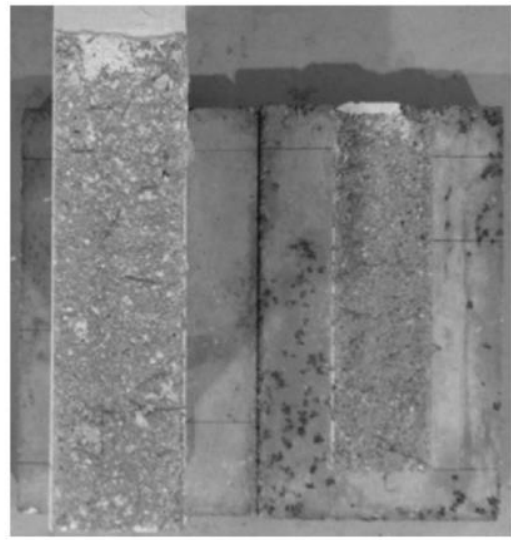

(b)

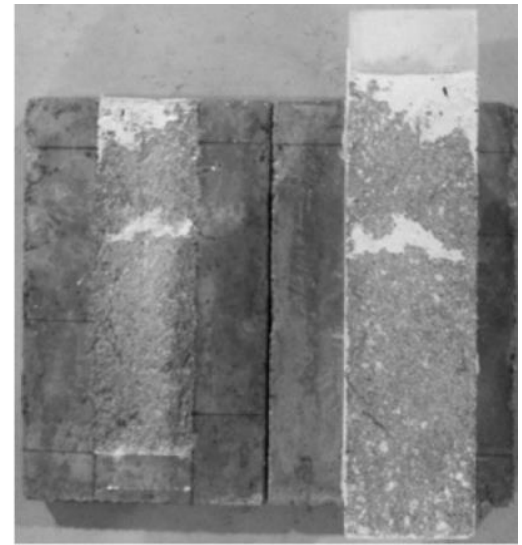

(c) 

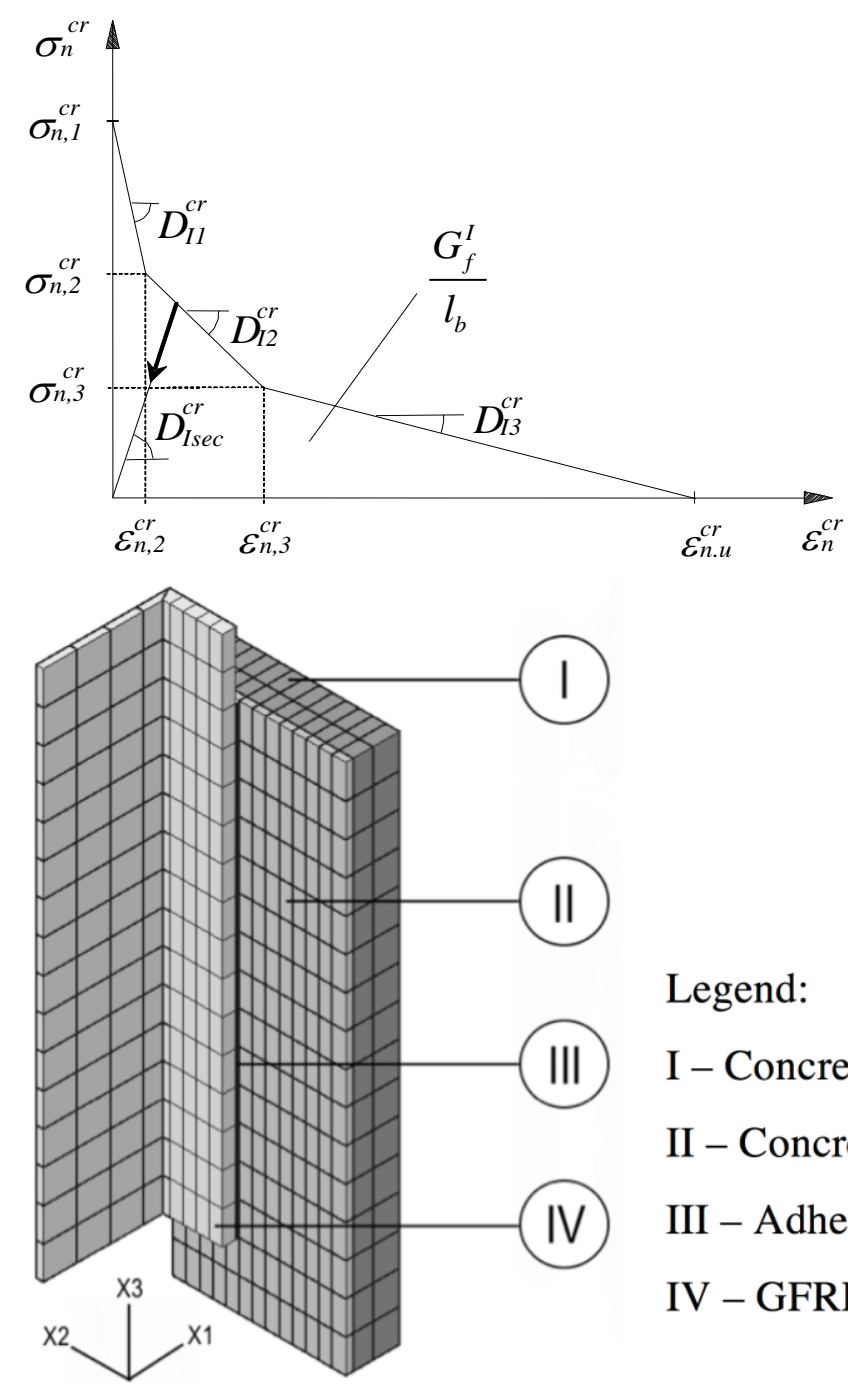

Legend:

I - Concrete panel with linear material behavior

II - Concrete panel with nonlinear material behavior III - Adhesive layer

IV - GFRP profile 


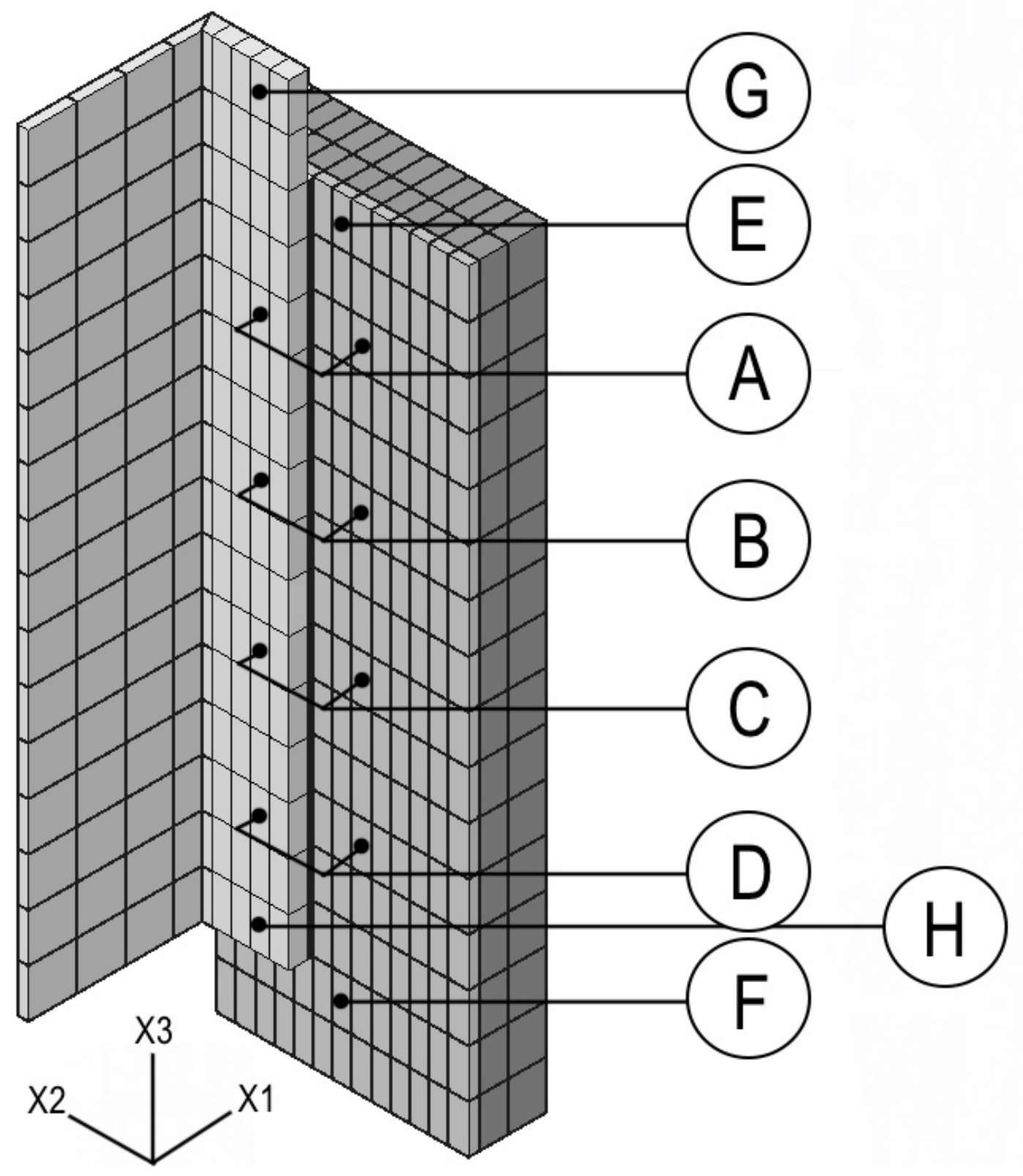




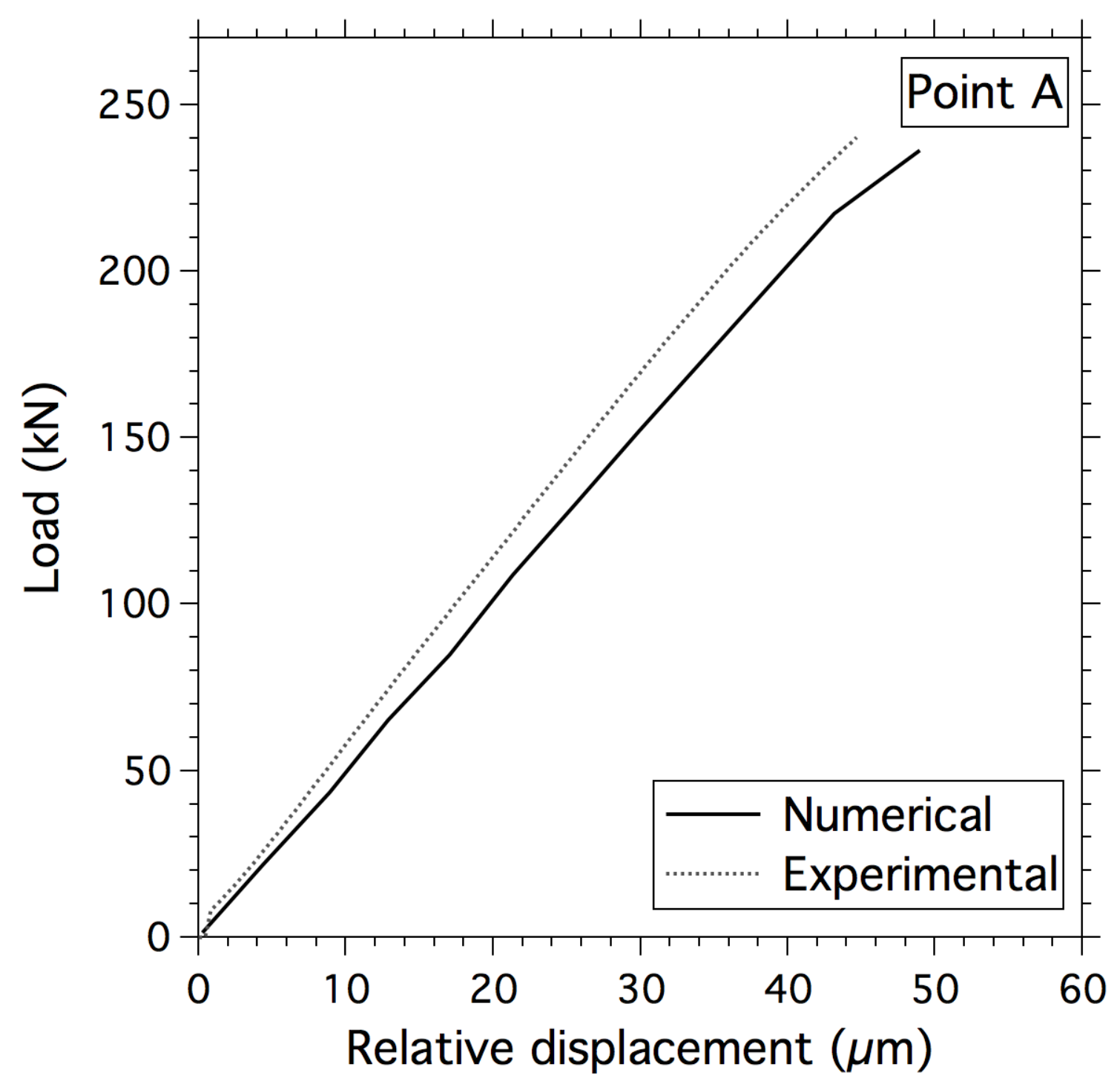




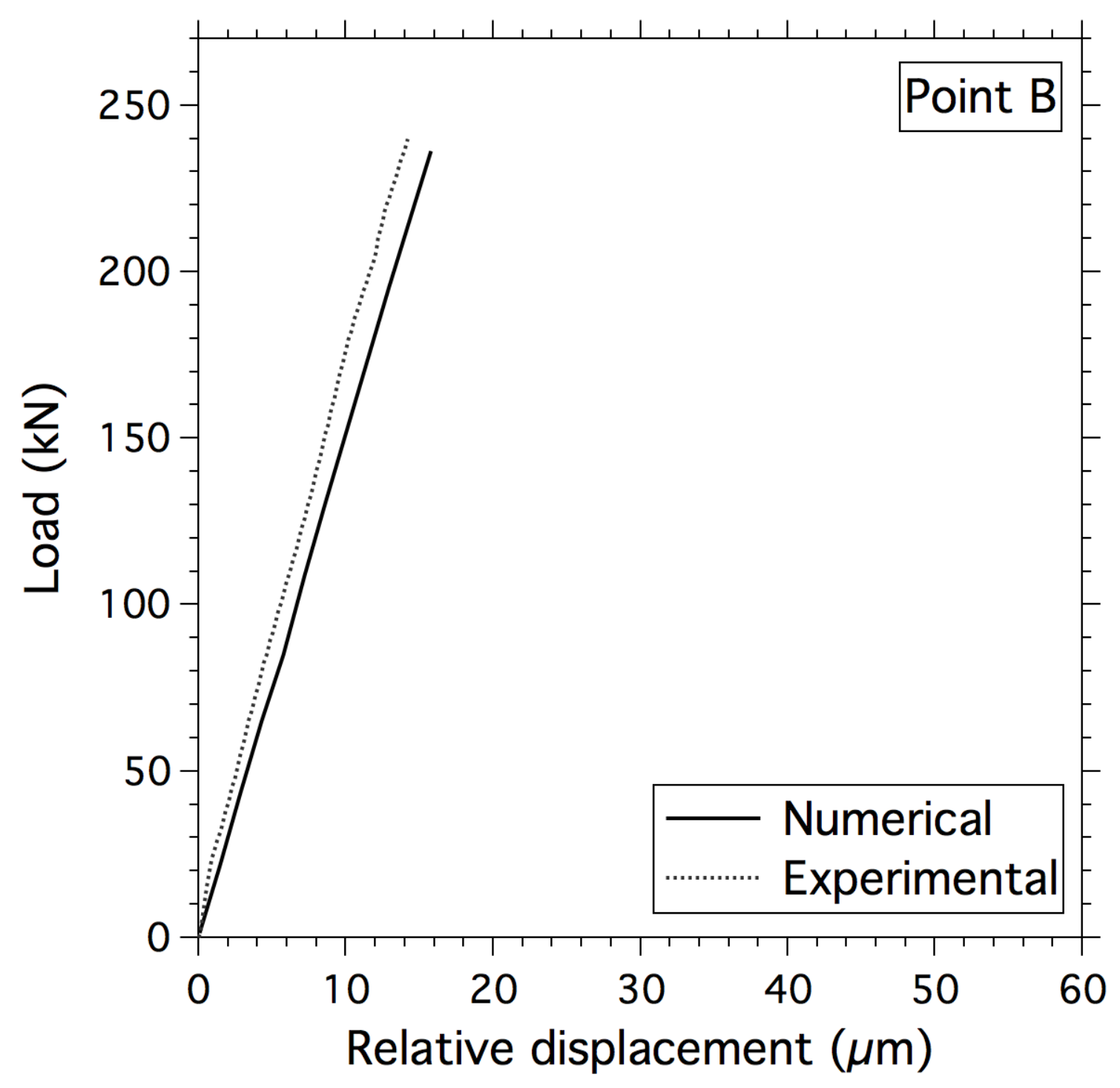




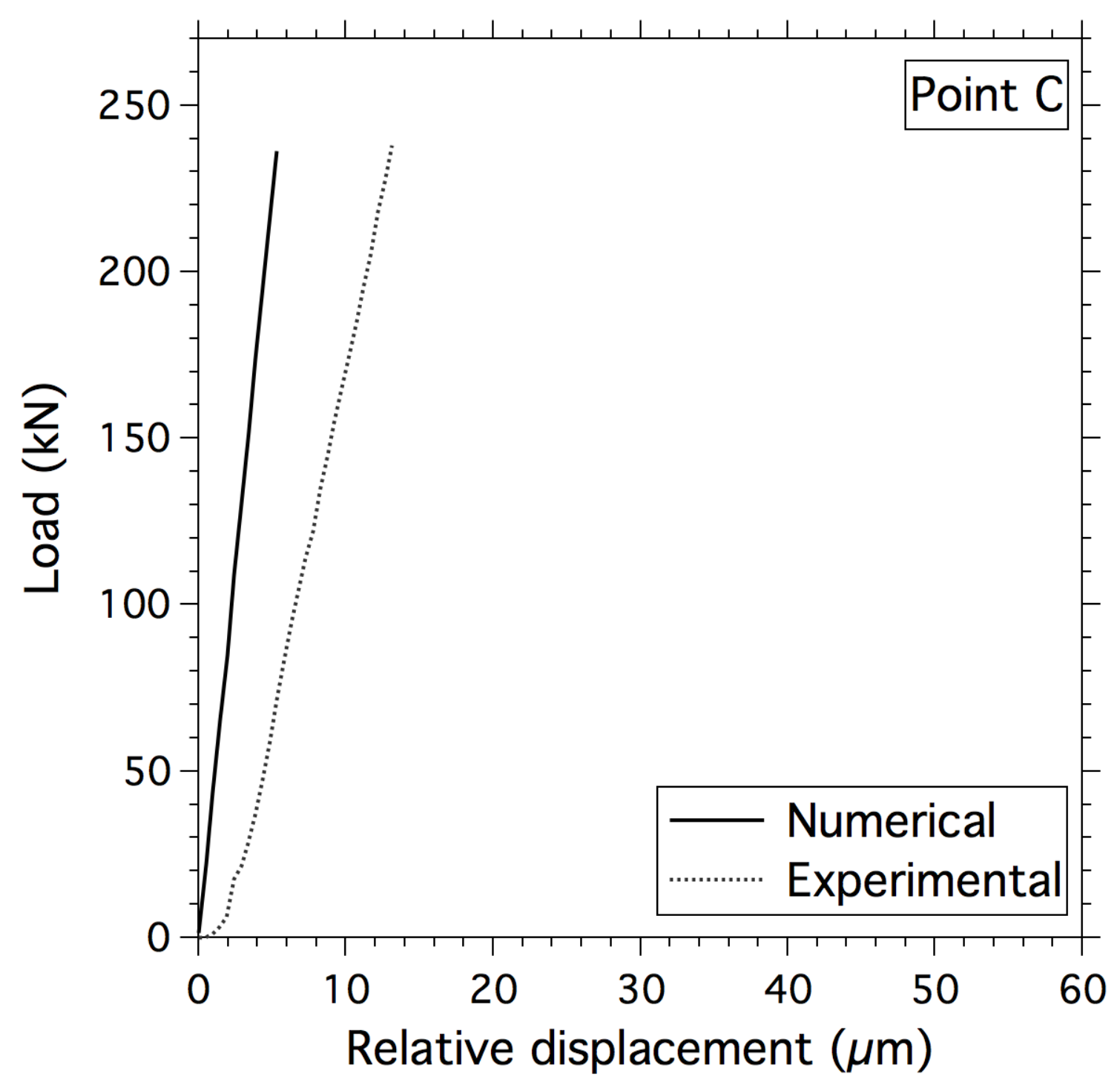




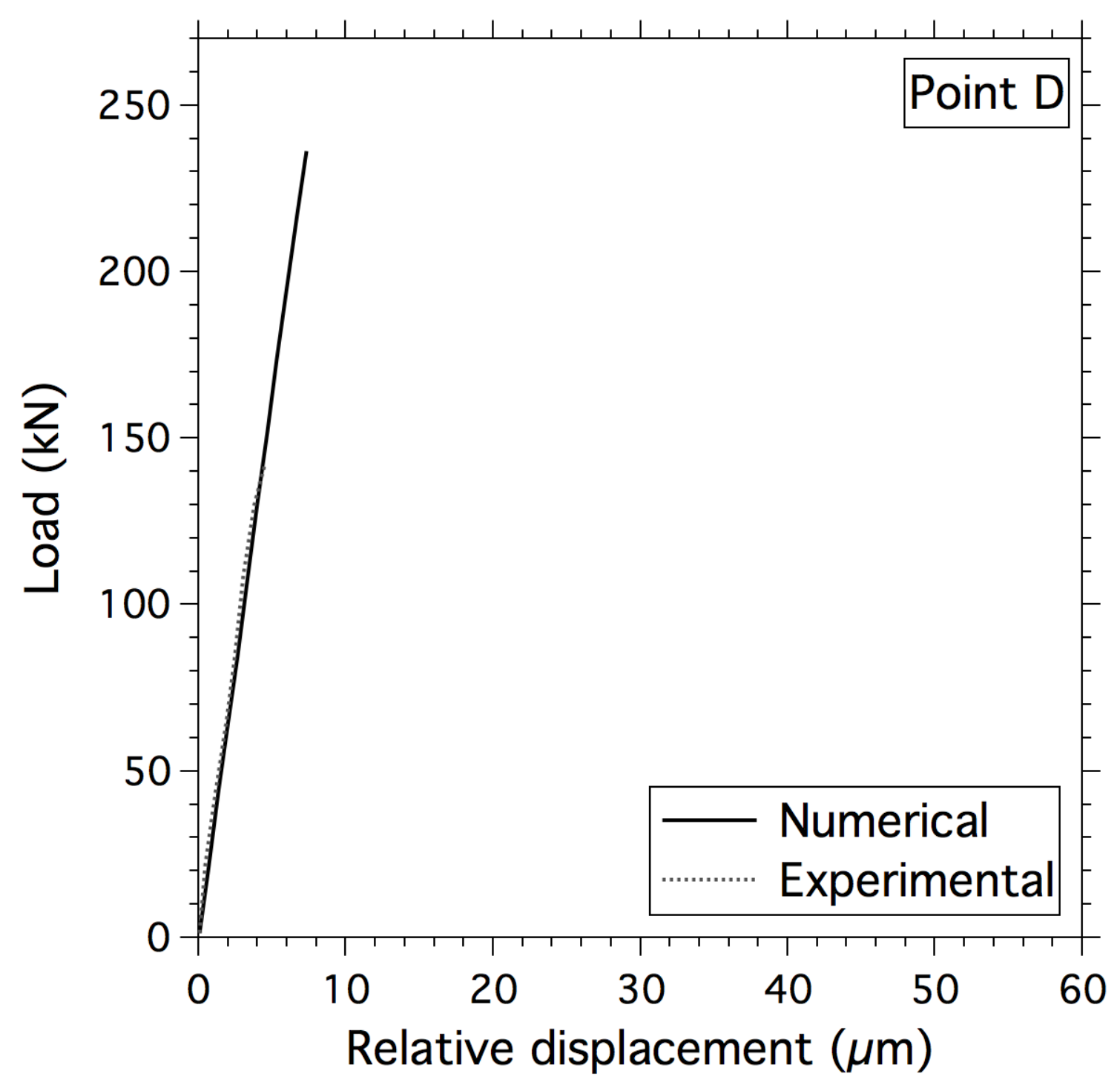




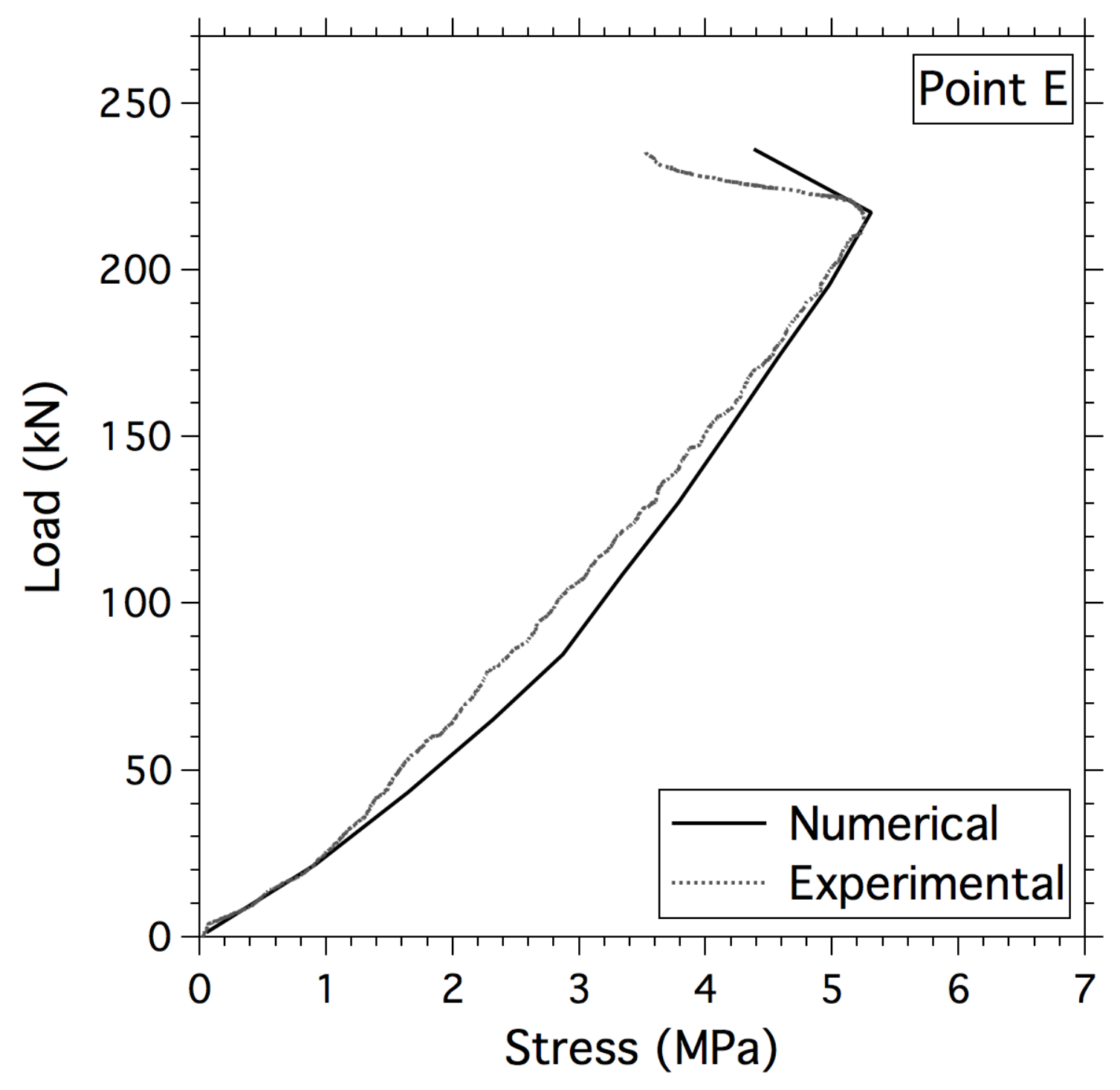




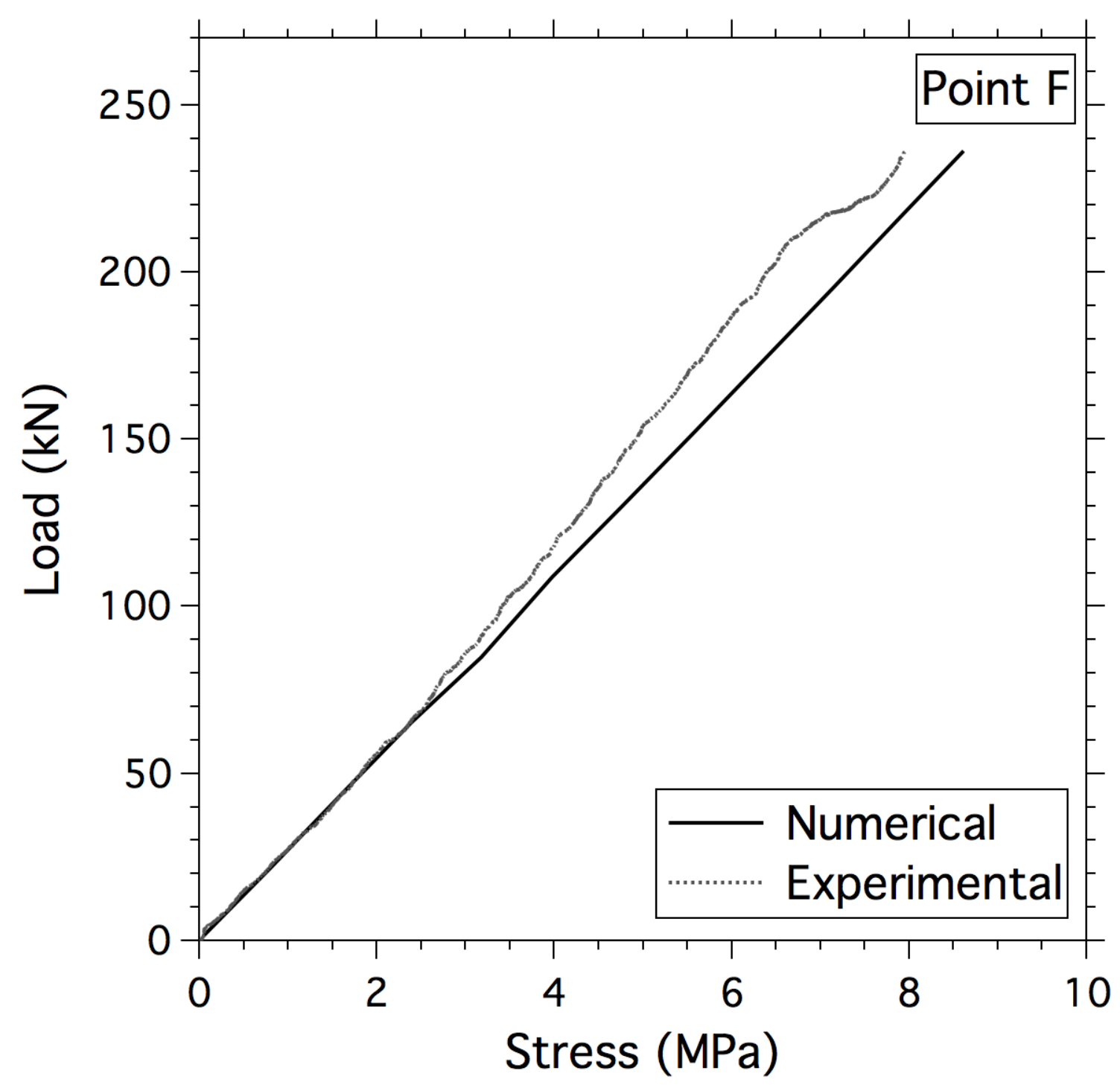




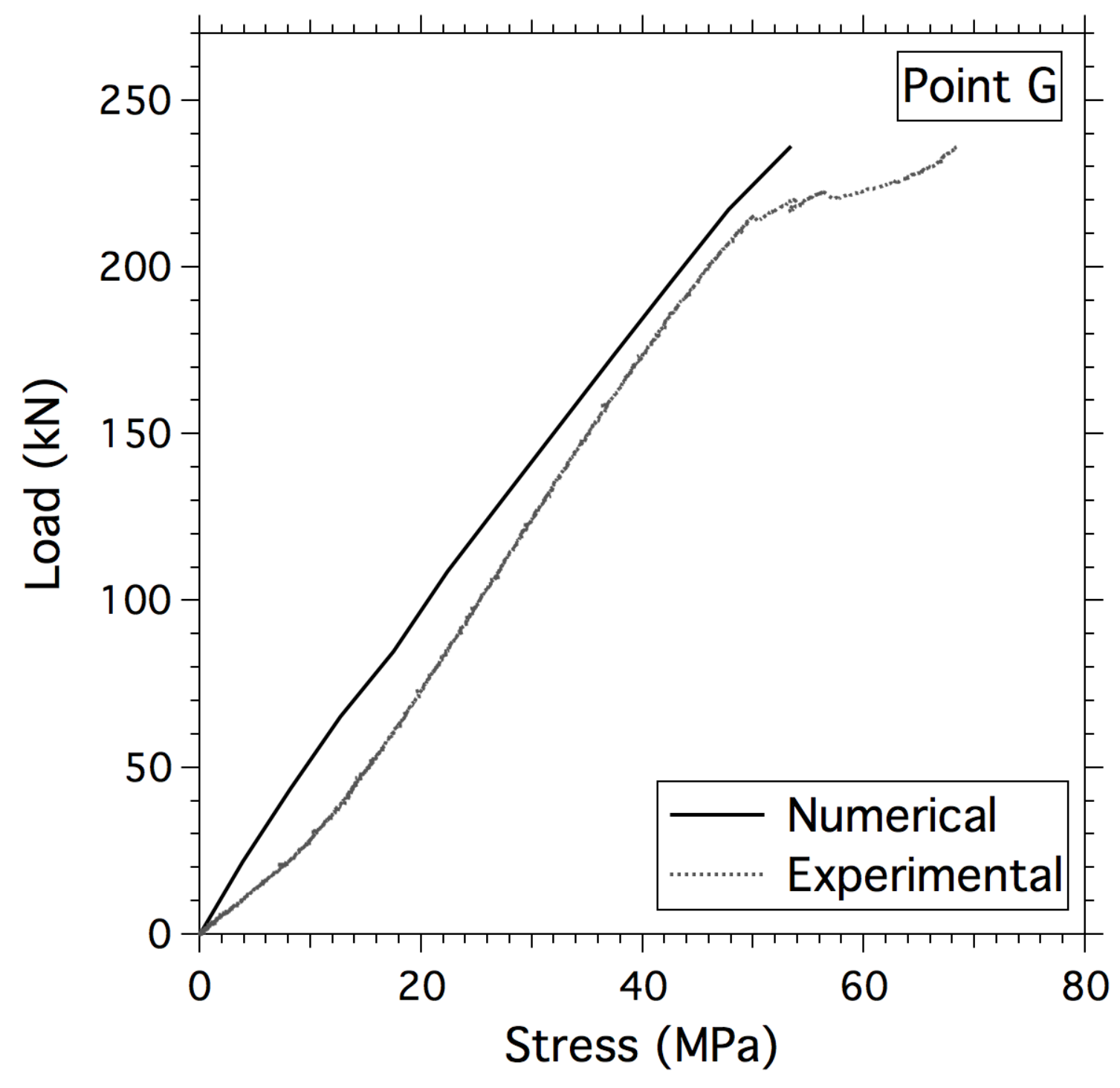




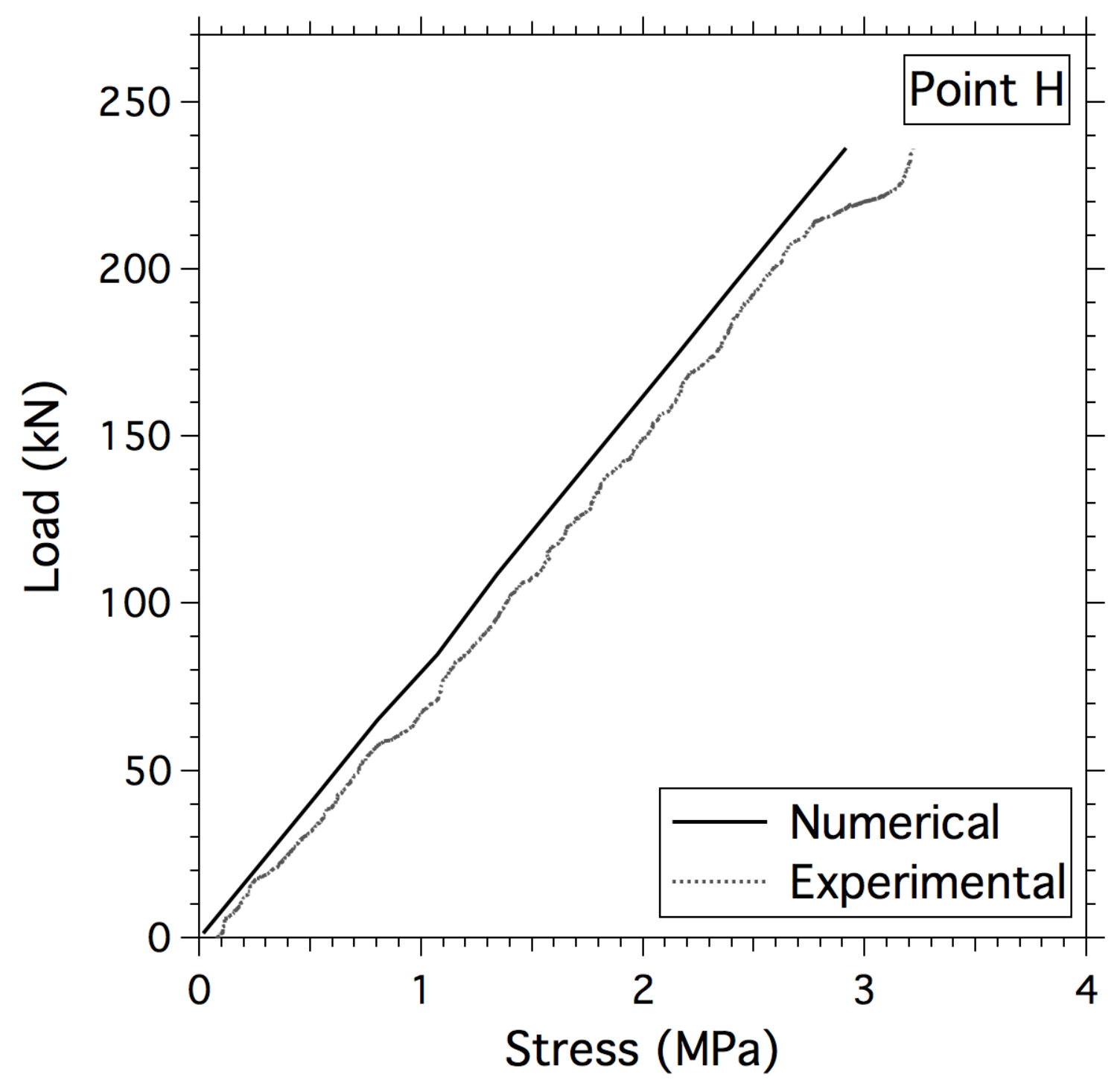

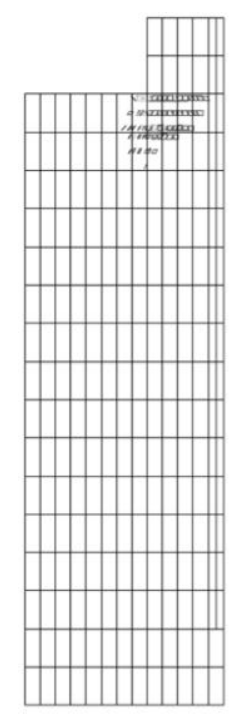

(a)

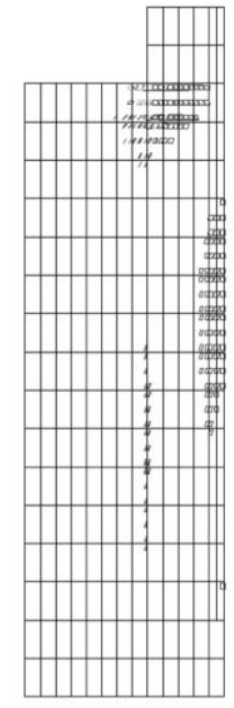

(b)

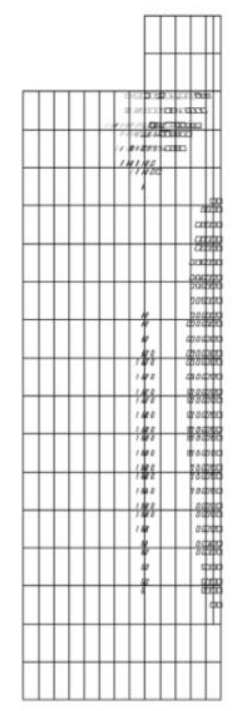

(c)

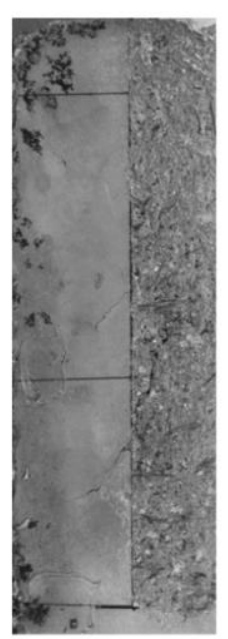

(d) 